\title{
Design of the third-generation lead-based neutron spallation target for the neutron time-of-flight facility at CERN
}

\author{
R. Esposito $\odot,{ }^{1,2, *}$ M. Calviani $\odot,{ }^{1, \dagger}$ O. Aberle, ${ }^{1}$ M. Barbagallo, ${ }^{1}$ D. Cano-Ott, ${ }^{3}$ T. Coiffet, \\ N. Colonna, ${ }^{4}$ C. Domingo-Pardo $\odot,{ }^{5}$ F. Dragoni, ${ }^{1}$ R. Franqueira Ximenes $\odot,{ }^{1}$ L. Giordanino, ${ }^{1}$ \\ D. Grenier, ${ }^{1}$ F. Gunsing,${ }^{6}$ K. Kershaw $\odot,{ }^{1}$ R. Logé $\odot,{ }^{2}$ V. Maire, ${ }^{1}$ P. Moyret, ${ }^{1}$ A. Perez Fontenla $\odot,{ }^{1}$ \\ A. Perillo-Marcone, ${ }^{1}$ F. Pozzi $\odot,{ }^{1}$ S. Sgobba $\odot,{ }^{1}$ M. Timmins, ${ }^{1}$ and V. Vlachoudis ${ }^{1}$ \\ (for the $n \_$TOF Collaboration) \\ ${ }^{1}$ European Laboratory for Particle Physics (CERN), 1211 Geneva 23, Switzerland \\ ${ }^{2}$ Thermomechanical Metallurgy Laboratory, PX Group Chair, \\ Ecole Polytechnique Fédérale de Lausanne (EPFL), 2002 Neuchâtel, Switzerland \\ ${ }^{3}$ Centro de Investigaciones Energéticas Medioambientales y Tecnológicas, Madrid, Spain \\ ${ }^{4}$ Istituto Nazionale di Fisica Nucleare, Bari, Italy \\ ${ }^{5}$ Instituto de Física Corpuscular, CSIC-Universitat de Valencia, Spain \\ ${ }^{6}$ CEA Saclay, Irfu, Gif-sur-Yvette, France
}

(Received 22 June 2021; accepted 13 August 2021; published 7 September 2021; corrected 26 May 2022)

\begin{abstract}
The neutron time-of-flight (n_TOF) facility at the European Laboratory for Particle Physics (CERN) is a pulsed white-spectrum neutron spallation source producing neutrons for two experimental areas: the Experimental Area 1 (EAR1), located $185 \mathrm{~m}$ horizontally from the target, and the Experimental Area 2 (EAR2), located $20 \mathrm{~m}$ above the target. The target, based on pure lead, is impacted by a high-intensity $20-\mathrm{GeV} / c$ pulsed proton beam. The facility was conceived to study neutron-nucleus interactions for neutron kinetic energies between a few $\mathrm{meV}$ to several $\mathrm{GeV}$, with applications of interest for nuclear astrophysics, nuclear technology, and medical research. After the second-generation target reached the end of its lifetime, the facility underwent a major upgrade during CERN's Long Shutdown 2 (LS2, 2019-2021), which included the installation of the new third-generation neutron target. The first- and second-generation targets were based on water-cooled massive lead blocks and were designed focusing on EAR1, since EAR2 was built later. The new target is cooled by nitrogen gas to avoid erosion-corrosion and contamination of cooling water with radioactive lead spallation products. Moreover, the new design is optimized also for the vertical flight path and EAR2. This paper presents an overview of the target design focused on both physics and thermomechanical performance, and includes a description of the nitrogen cooling circuit and radiation protection studies.
\end{abstract}

DOI: 10.1103/PhysRevAccelBeams.24.093001

\section{INTRODUCTION AND MOTIVATIONS}

The neutron time-of-flight (n_TOF) facility at the European Laboratory for Particle Physics (CERN) is a neutron source capable of providing high-intensity pulsed white-spectrum neutrons covering almost 11 orders of magnitude, from thermal neutrons to several $\mathrm{GeV}$. Neutrons are produced via spallation mechanism [1] from

\footnotetext{
raffaele.esposito@cern.ch
}

marco.calviani@cern.ch

Published by the American Physical Society under the terms of the Creative Commons Attribution 4.0 International license. Further distribution of this work must maintain attribution to the author(s) and the published article's title, journal citation, and DOI. the interaction between a pure-lead target and pulsed $20-\mathrm{GeV} / c$ proton bunches from the Proton Synchrotron (PS) accelerator ring at CERN. The generated neutrons travel inside vacuum tubes along two flight paths directed to two experimental areas, Experimental Area 1 (EAR1) and Experimental Area 2 (EAR2), where cutting-edge experimental setups for neutron-induced reaction studies are in place. EAR1 is located at the end of a horizontal beam line, $185 \mathrm{~m}$ from the spallation target, while EAR2 is located at the end of a vertical beam line, $20 \mathrm{~m}$ above the target (Fig. 1). The facility was conceived to study neutron-nucleus interactions with applications of interest for nuclear astrophysics, nuclear technology, and medical research [2-6].

The facility operated with EAR1 and a first-generation spallation target (Target \#1) from 2000 to 2004 [7]. 


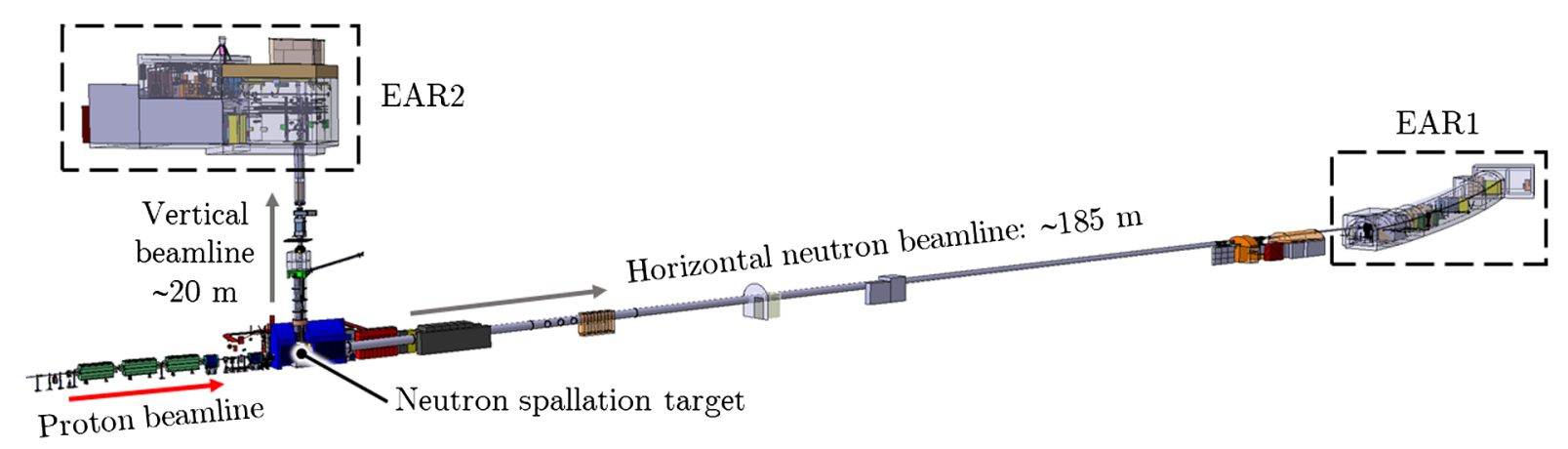

FIG. 1. The n_TOF Facility. A high-intensity proton beam from the CERN's Proton Synchrotron collides with a pure lead target, producing neutrons that travel along two flight paths toward two experimental areas: EAR1 and EAR2. EAR1 is located $185 \mathrm{~m}$ from the target, while EAR2 is located $20 \mathrm{~m}$ above the target.

A second-generation target (Target \#2) operated from 2008 to the end of 2018. Even though the second target included many upgrades if compared with the first one, both targets were cooled by water in direct contact with pure lead [8].

For the first target, the cooling water was used as moderator. An independent moderator assembly made from aluminum alloy (EN AW-5083 H111) was added to the second-generation target to separate the cooling water from the liquid used for moderation. The moderator liquid was then switched to borated water $\left(1.28 \mathrm{wt} \%\right.$ with ${ }^{10} \mathrm{~B}$-enriched boron at 99\%), which reduced the $\gamma$-ray background for the neutron capture measurements in EAR1 [9] (the $\gamma$-ray background in n_TOF is described in detail in Sec. II C).

The second-generation target was designed considering an estimated lifetime of ten years. In the last years of target operation, an increase in the cooling water activity was detected, and preliminary signs of corrosion of the neutron window were observed by endoscopic inspections [10]. Moreover, during 2014, the second experimental area (EAR2) was built $20 \mathrm{~m}$ above the spallation target, although the neutron beam characteristics in EAR2 were not optimal since the target shape was not conceived for this experimental area.

All these aspects triggered the design of a new thirdgeneration spallation target (Target \#3), to be installed during the Long Shutdown 2 (LS2), a three-year stop of the CERN accelerators, and with the objective of starting operation in 2021. High-purity lead has been kept as the core material owing to its superior performances in terms of reduced photon background with respect to other spallation materials, due to its very low neutron capture cross sections.

Target \#3 was designed with the assumption of a beam momentum of $20 \mathrm{GeV} / c$, with a maximum number of protons per pulse equal to $10^{13}$ (equivalent to a pulse kinetic energy of $32 \mathrm{~kJ}$ ). The minimum pulse period is $1.2 \mathrm{~s}$ and the maximum average intensity allowed is $1.67 \times 10^{12} \mathrm{p}^{+} / \mathrm{s}$, corresponding to an average power on target of $5.4 \mathrm{~kW}$. With a pulse duration of $7 \mathrm{~ns}(\mathrm{rms})$, this yields a peak deposited power of $1.8 \mathrm{TW}$. The beam size on target is assumed to be $15 \mathrm{~mm}$ (rms).

\section{A. Pulsed white neutron sources}

Several white neutron sources are operating worldwide, each of them with specific characteristics and features, depending on the specific user requests [11]. However, only a few of them are pulsed and thus optimized for time-of-flight measurements. They are generally characterized by relatively high instantaneous neutron flux with very reduced photon background. The GELINA facility at the Joint Research Centre in Geel (Belgium) is based on a linear electron accelerator impinging on a mercury-cooled uranium target $[12,13]$. The Gaerttner LINAC Center at the Rensselaer Polytechnic Institute in the United States employs a water-cooled tantalum target impacted by an electron beam [14,15]. Tantalum-clad tungsten targets are employed in the Lujan Center at the Los Alamos Neutron Source Center (LANSCE) in the United States [16].

Neutron production targets based on lead are employed at the Spallation Neutron Source of the Swiss Institute for Nuclear Research (SINQ) at the Paul Scherrer Institute (PSI) in Switzerland [17] and in the neutron time-of-flight setup of the Electron Linac for beams with high Brilliance and low Emittance (nELBE) at the Helmholts-Zentrum Dresden-Rossendorf in Germany [18]. In the case of the SINQ source, the lead is solid without beam but operates in liquid state inside a Zircalloy cladding during operation [19-21], while in the case of nELBE lead is in the liquid state at all times. Solid lead targets for neutron production are utilized for the lead slowing-down spectrometer at the LANSCE facility [22].

\section{PHYSICS REACH}

The $n \_$TOF facility has been at the forefront of neutron physics since 2001 [23]. The design of Target \#3 aims to further expand the measuring capabilities of the facility [8]. The combination of a high-energy and high-intensity proton beam, long flight paths, specifically designed optical elements along the beam lines, and an innovative spallation target results in high quality neutron beams 
TABLE I. Key features of the n_TOF facility [9,24].

\begin{tabular}{|c|c|c|c|}
\hline \multicolumn{2}{|l|}{ Quantity } & EAR1 & EAR2 \\
\hline \multicolumn{2}{|c|}{ Neutron flux(n/bunch) } & $10^{6}$ & $10^{8}$ \\
\hline Energy range & $\begin{array}{l}\text { Minimum } \\
\text { Maximum }\end{array}$ & $\begin{array}{c}\text { Subthermal } \\
1 \mathrm{GeV}\end{array}$ & $\begin{array}{c}\text { Subthermal } \\
100 \mathrm{MeV}\end{array}$ \\
\hline \multicolumn{2}{|c|}{ Best resolution $(\Delta \mathrm{E} / \mathrm{E})$} & $10^{-4}$ & $10^{-3}$ \\
\hline
\end{tabular}

making $\mathrm{n} \_$TOF a unique facility. The main features of the facility are summarized in Table I.

Extensive Monte Carlo studies, performed by means of the FLUKA simulation package $[25,26]$, were conducted in parallel with the engineering design of Target \#3 to help solving the issues of Target \#2 mentioned in Sec. I and further improve physics performance. A detailed and comprehensive FLUKA model of the target assembly was developed, based on the engineering design described in the next sections. The guiding goals of the Monte Carlo studies were, compared to Target \#2: (1) Preserve intensity and shape of the neutron flux in the direction of EAR1. (2) Improve the resolution function for EAR2. (3) Reduce the $\gamma$-ray background in EAR1.

The next subsections provide an account of these optimization studies and their results.

\section{A. Neutron fluence}

The key feature for both experimental areas is the high instantaneous neutron flux $[9,24,27]$, of fundamental importance for measuring cross sections of radioactive samples or samples available in small quantities. The integrated flux of $10^{6}$ and $10^{8}$ neutrons/bunch in EAR1 and EAR2, respectively, is due to the high intensity and high energy of the primary proton beam and the overall mass of the target (especially its lead component).

As shown in Fig. 2, Target \#3 produces values of the neutron flux similar to Target \#2.

The shape of the neutron beam and, to some extent, its intensity, also depend on the moderator systems. When compared to Target \#2, Target \#3 has a slightly thinner layer of moderator liquid (water or borated water) crossed by neutrons directed towards EAR1. This results in an additional contribution of nonmoderated neutrons at the evaporation peak (hundreds $\mathrm{keV}$ to several $\mathrm{MeV}$ ) and, consequently, in a slightly lower neutron flux in the thermal and epithermal regions $(\leq 100 \mathrm{eV})$. Overall, the neutron flux reaching EAR1 with Target \#3 is $10 \%$ lower than with Target \#2. Regarding EAR2, Target \#3 leaves the neutron flux in the range $25 \mathrm{meV}-100 \mathrm{keV}$ essentially unchanged, while a factor $2-3$ higher is expected at the evaporation peak. The higher flux is only indirectly related to the new target design, as it depends mainly on the new design of the vacuum window coupling the target to the beam line.

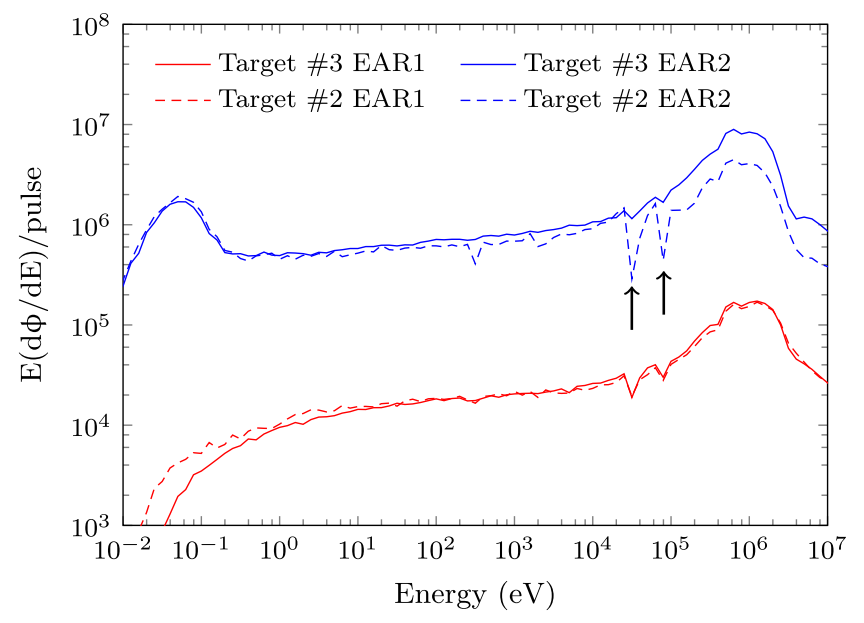

FIG. 2. FLUKA simulation of the neutron flux in the two experimental areas for Targets \#2 and \#3. The neutron flux in the energy range of interest is similar in EAR1 and much better for Target \#3 in EAR2, especially considering the absence of absorption dips in the tens of $\mathrm{keV}$ range.

Moreover, the smaller amount of aluminum present in the structure of the Target \#3 ensures a substantial reduction of the related absorption dips in the flux, as indicated by the black arrows in Fig. 2.

\section{B. Resolution function}

The neutron-induced reaction cross sections under investigation at n_TOF exhibit narrow resonances in the eV-keV region. The energy resolution of the facility is of utmost importance to accurately determine the cross sections in this energy range. Energy resolution essentially depends on the flight path of the two beam lines and on the neutron moderation. The resolution function can be expressed as the uncertainties $\mathrm{d} \lambda$ in the equivalent flight path distance, and it is purely dictated by the geometry of the moderator. In the energy range of interest it is characterized by a dominant peak having a full width at half maximum (FWHM) of $2 \mathrm{~cm}$, due to the pronounced slowdown in water, and a relatively small but long tail (up to several meters), due to the moderation in the lead core.

FLUKA simulations showed that the optimum, in terms of FWHM, can be reached with water layers of $4 \mathrm{~cm}$ for both EAR1 and EAR2 moderators. While the new design does not show any difference in the EAR1 resolution function when compared to Target \#2 [27], it significantly improves the scenario for EAR2. In the Target \#3 design, particular attention was paid in making the neutrons traveling towards EAR2 pass through a uniform layer of moderator water. This was not the case for Target \#2, built before the construction of the second beam line and therefore not optimized for it. Figure 3 shows the comparison of the $\lambda$ distribution of neutrons in EAR2 in the energy range $1-10 \mathrm{eV}$ for the two targets, revealing a double-peak structure for Target \#2 that led to substantial limitations 


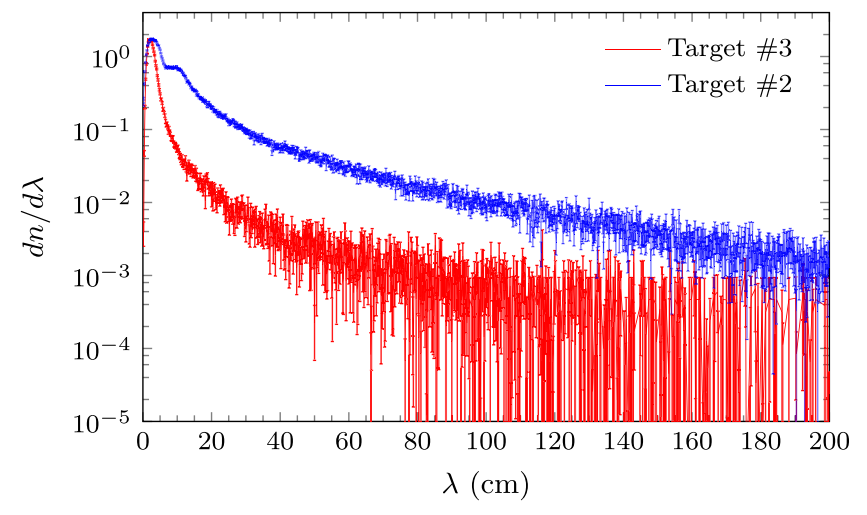

FIG. 3. Distribution of the moderation length $\lambda$, in EAR2, for neutrons in the energy range $1-10 \mathrm{eV}$. Target \#2 exhibits a double-peak structure leading to substantial limitations on the measurements in EAR2, whereas Target \#3 exhibits a single peak with narrower FWHM, which is better suited for high-resolution measurements.

on the measurements in EAR2. The double-peak structure is not present in the $\lambda$ distribution of Target \#3, characterized by a much better FWHM around the peak.

\section{Background}

A low background is a fundamental prerequisite to carry out high-quality cross-section measurements. At n_TOF, the two main components of background related to the spallation target are neutrons and $\gamma$-rays.

The neutron contribution is proportional to the neutron flux and also depends on the optical elements placed in the downstream beam lines (i.e., collimators), so it is essentially unchanged in the new design. The contribution of $\gamma$-rays is strongly dependent on the target assembly, in particular on the moderator system and on the structural materials of the target. The $\gamma$-rays reaching the experimental areas can be divided into two contributions: prompt and delayed. The threshold between the two has been set at $900 \mathrm{~ns}$ for EAR1 and $200 \mathrm{~ns}$ for EAR2.

The prompt $\gamma$-rays reach EAR1 within $900 \mathrm{~ns}$ and EAR2 within $200 \mathrm{~ns}$. Their amount is directly proportional to the length of lead crossed by the primary proton beam, so no sizable differences are expected in the new target design with regard to EAR1. For EAR2, on the other hand, the coupling between target and beam line has been improved with a new optimized shape of the vacuum chamber, so a larger portion of the spallation target is seen by the experimental area and the $\gamma$-ray contribution to the background increases by a factor of 6 . To compensate for the higher background, a 5-cm thick lead plate has been integrated just above the target core and below the EAR2 moderator. FLUKA simulations indicate that the addition of this lead plate is enough to keep the prompt $\gamma$-ray contribution to the background in EAR2 as low as for Target \#2, with no significant reduction in the neutron flux reaching the area.

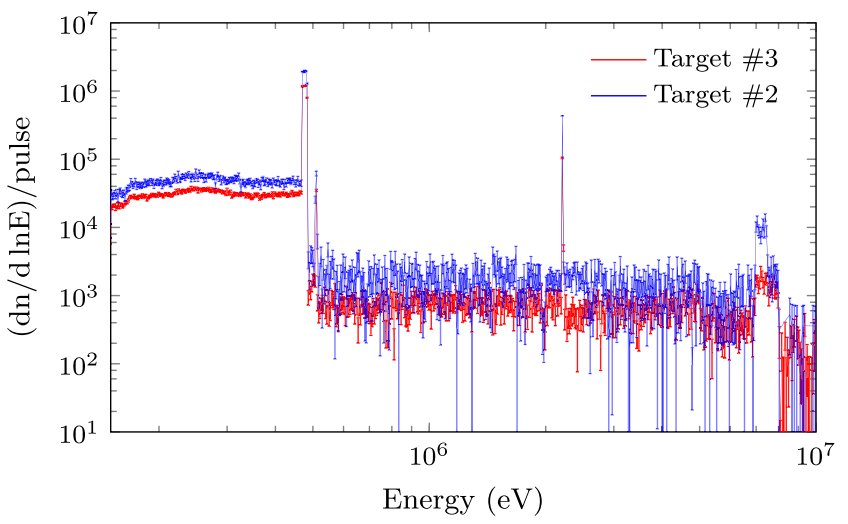

FIG. 4. Delayed $\gamma$-ray distribution in EAR1 for Target \#2 (blue) and Target \#3 (red). A reduction by a factor 4-5 is visible in Target $\# 3$ at the $2.2-\mathrm{MeV}$ energy peak and at the $7-\mathrm{MeV}$ transition lines.

The delayed $\gamma$-rays reach EAR1 and EAR2 at a time-offlight longer than 900 and $200 \mathrm{~ns}$, respectively. They are generated from radiative capture reactions of neutrons in the hydrogen of the moderator water and in the structural materials of the target. The former can be inhibited using borated water (due to thermal neutron capture in ${ }^{10} \mathrm{~B}$ ). For this reason, Target \#3 includes two decoupled moderator circuits, with the possibility of changing independently the circulating moderator liquid. In addition, considerable effort was put into minimizing the structural materials of the target that are sources of delayed $\gamma$-rays. Figure 4 shows the FLUKA results of the delayed $\gamma$-ray background expected in EAR1 in comparison to Target \#2, revealing a background lower by a factor 4-5, in particular at the 2.2-MeV energy peak and at the 7-MeV transition lines.

Regarding EAR2, $\gamma$-ray background arises mainly from the interaction of neutrons with the collimator at the entrance of the experimental area and with the beam dump in the roof of the building. Therefore, the design of the target does not impact the delayed $\gamma$-ray background in EAR2.

\section{MECHANICAL DESIGN}

The new Target \#3 assembly is shown, in exploded view, in Fig. 5: housed inside a stainless steel vessel, six lead slices are cooled by gaseous nitrogen and are supported by precisely machined anticreep plates. These are made from aluminum alloy and include the channels through which the cooling fluid flows. The cooling gas is distributed through two main arteries inside a cradle made from aluminum alloy, which supports the lead core from below. Connected to the vessel, two moderator containers, made from aluminum alloy, are positioned on the path of the neutrons directed to the two experimental areas. The bond between the stainless steel vessel and the aluminum moderator is obtained by an explosive-bonded joint. The lead slices are $5-\mathrm{cm}$ thick, with the exception of the slice close to the 


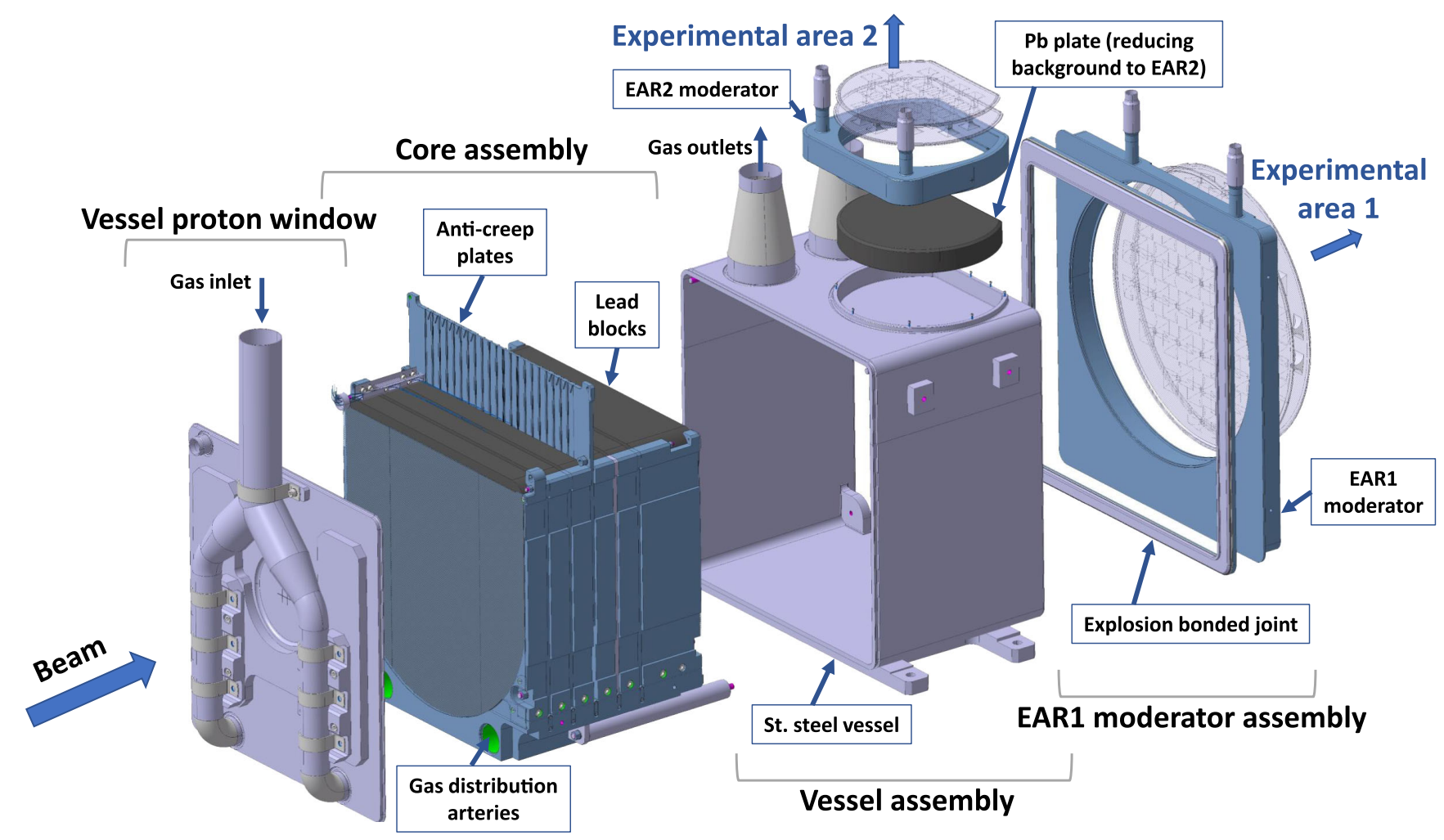

FIG. 5. Exploded model of the target. The cooling nitrogen gas flows through the channels machined into the anticreep plates. The inner core is enclosed in an AISI 316L stainless steel vessel. The two moderators are in aluminum EN AW-5083 H112. The EAR1 moderator is bonded to the stainless steel vessel by a bimetallic transition obtained by explosive bonding.

EAR1 moderator, which is $15-\mathrm{cm}$ thick. These values were selected to obtain a reasonable compromise between the total target length and lead surface exposed to the coolant. FLUKA simulations showed a conspicuous reduction in $\gamma$-ray background and an increase in neutron flux by merging the $15 \mathrm{~cm}$ of lead closest to the EAR1 moderator into a single slice. Figure 6 shows a photo of the target core inside the stainless steel vessel before the proton side of the vessel was welded on to close it.

\section{A. Lead core and anticreep structure}

The main target core is composed of six slices of highpurity lead supported by an aluminum (EN AW-6082 T6) structure that includes anticreep plates between the slices (Fig. 5). The lead grade is UNS L50006, with a minimum purity of $99.98 \mathrm{wt} \%$. The anticreep aluminum structure also plays a determinant role in the gas distribution thanks to channels machined to distribute optimally the nitrogen gas between the lead slices.

To ensure a correct assembly of the anticreep plates between the lead slices, the gap between them must be within 45 and $195 \mu \mathrm{m}$. The minimum value takes the thermal expansion of the lead slices during operation into account, while the maximum value is required to avoid any negative impact on the nitrogen flow. This requirement entails the anticreep plates to be manufactured with tight dimensional tolerances with respect to thickness $(9.85 \pm 0.05 \mathrm{~mm})$ and tight geometrical tolerances (flatness lower than $1 \mathrm{~mm}$ ). The large size of the plates $(0.6 \mathrm{~m} \times 0.6 \mathrm{~m})$ made this requirement particularly difficult to keep while milling the channels, since each milling step can bring distortions to the plate. The accumulation of deformations along the same direction was avoided by changing the side of the plate after each milling step. Furthermore, a dedicated vacuum table holding the plates during the milling procedure was manufactured, and the whole procedure was tuned and tested by first building a prototype of the plate.

\section{B. Vessel and moderator design}

The target core is contained in a stainless steel (AISI 316L) vessel designed to hold a nominal nitrogen pressure of 0.5 bar. Made by first welding two u-shaped parts, the upstream side is closed by a plate equipped with the nitrogen inlet pipes, and welded once the target core was inserted (Fig. 5). A beam window was machined at the beam impact area by locally reducing the vessel thickness down to $3 \mathrm{~mm}$ to avoid significant heat dissipation due to the interaction between the proton beam and the vessel. An additional stainless steel neutron window (4-mm thick) was welded by electron beam to the top of the vessel and supports the lead plate that reduces the $\gamma$-ray 


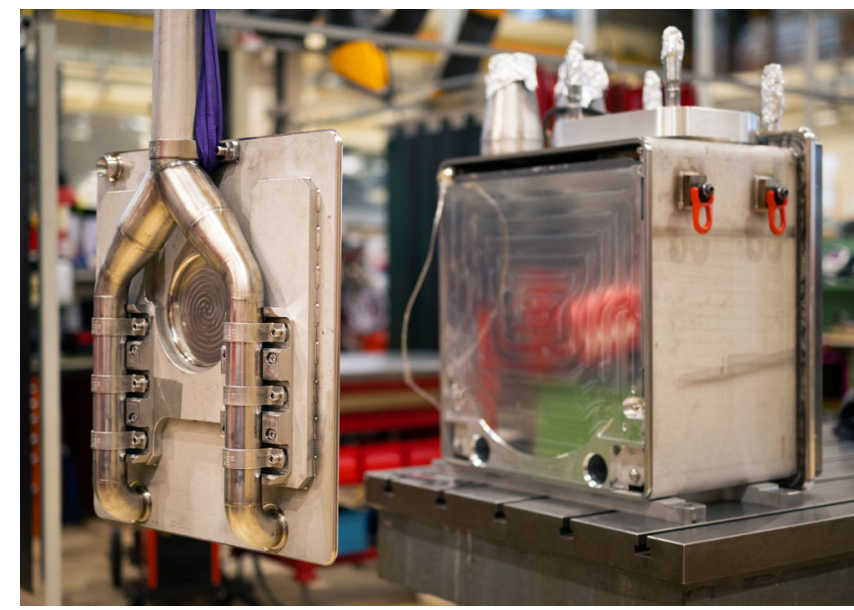

FIG. 6. Photo of the n_TOF Target \#3 core inside the stainless steel vessel before closing the proton side of the vessel by TIG (tungsten inert gas) welding.

background in EAR2 mentioned in Sec. II C. The two moderators are connected to two independent water circuits at a nominal pressure of $2.5 \mathrm{bar}$. They are made from forged aluminum EN AW-5083 H112. This alloy was chosen for its good mechanical properties, their stability after welding, good general corrosion resistance, and the ability to withstand the stresses induced by nitrogen pressure and thermal gradients. The EAR2 moderator is located outside the vessel, placed on top of the 5 -cm lead plate above the target core. The moderator is bolted to the vessel and sealed at the top edge to prevent moisture building up between it and the lead plate.

The EAR1 moderator, the larger of the two, was manufactured by deep-milling technology, which reduced the number of welds needed but required a rigorous production-process qualification to ensure the necessary dimensional tolerances. This moderator is an integral part of the vessel. The transition between the aluminum alloy of the moderator and the stainless steel vessel is a rectangularshaped strip cut out from an explosive-bonded plate. The challenge of such a solution lies in the qualification of the bimetallic plates available from industry and on the design of the interfaces between the different parts to ensure the desired gas tightness for the entire lifetime of the target. The transition from aluminum alloy (EN AW-5083 H112) to stainless steel (AISI 316L) includes two additional ductile layers of pure aluminum (EN AW-1050A H14) and pure titanium (grade 1) to ensure the good quality of the explosive bonding process (Fig. 7). To validate the quality of the bond in terms of impurities, voids, and mechanical resistance, CERN established strict specifications and quality controls: the bond was subjected to helium leak tests (maximum leak rate accepted: $10^{-7} \mathrm{mbar} \mathrm{L} / \mathrm{s}$ ), and a dye penetrant inspection was performed in accordance with the EN 10228-2 standard on 100\% of the machined surfaces. Ultrasonic tests were carried out for each

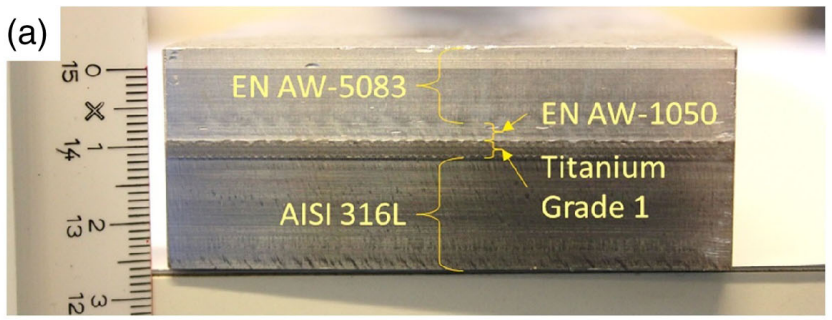

(b)

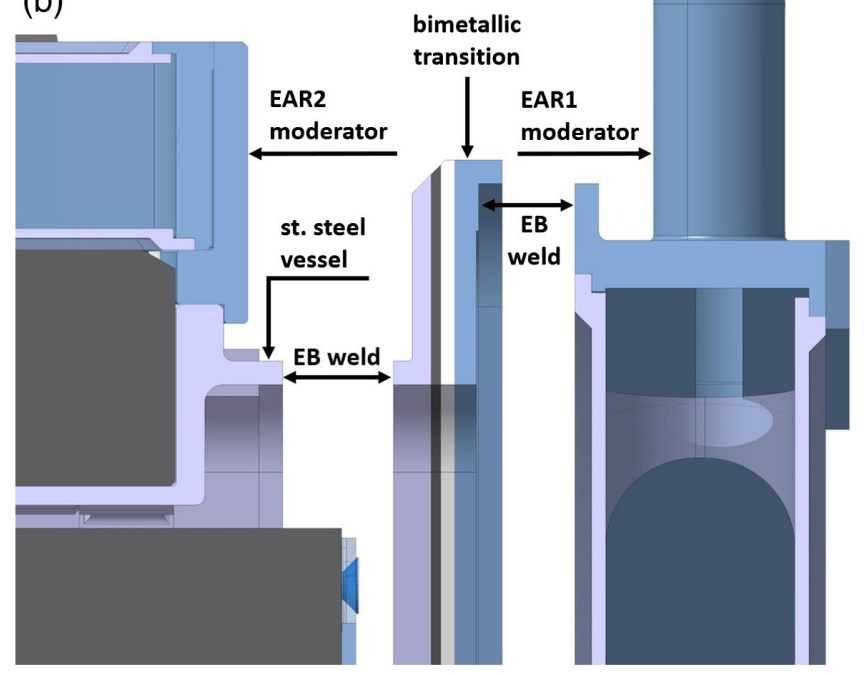

FIG. 7. (a) Cross-cut of the explosive-bonded bimetallic transition between the stainless steel target vessel and the aluminum EN AW-5083 H112 EAR1 moderator. (b) Schematic view of the explosive-bonded vessel-moderator connection.

explosive-bonded interface according to EN 10288-4, along with metallographic inspections.

In addition to the nondestructive examinations, tensile tests and post-weld metallographic investigations were carried out on representative samples extracted from the original explosive-bonded plate. The tensile tests confirmed a bond strength of $105 \mathrm{MPa}$, higher than the minimum acceptable value of $80 \mathrm{MPa}$ and limited by the strength of the weakest base material, aluminum EN AW-1050A H14 (Fig. 8). The post-weld metallographic investigations confirmed that, after electron-beam welding the explosivebonded joint to the moderator, the heat-affected zone is confined far from the interfaces of the bimetallic transition within a safe distance of $3 \mathrm{~mm}$, and thus it does not affect them.

A first prototype of the explosive-bonded joint, 3-mm thick, failed the leak validation. A second prototype was built to find a safe thickness value for the joint: the prototype was designed to easily perform leak tests and reduce thickness by milling. After each leak test, the thickness of the prototype was reduced in steps of $5 \mathrm{~mm}$, starting from $28 \mathrm{~mm}$ and down to $8 \mathrm{~mm}$ : no leak was detected at any iteration. It was concluded that, rather than its thickness, the main factor determining the soundness of a leak-tight joint is the choice of the original region 

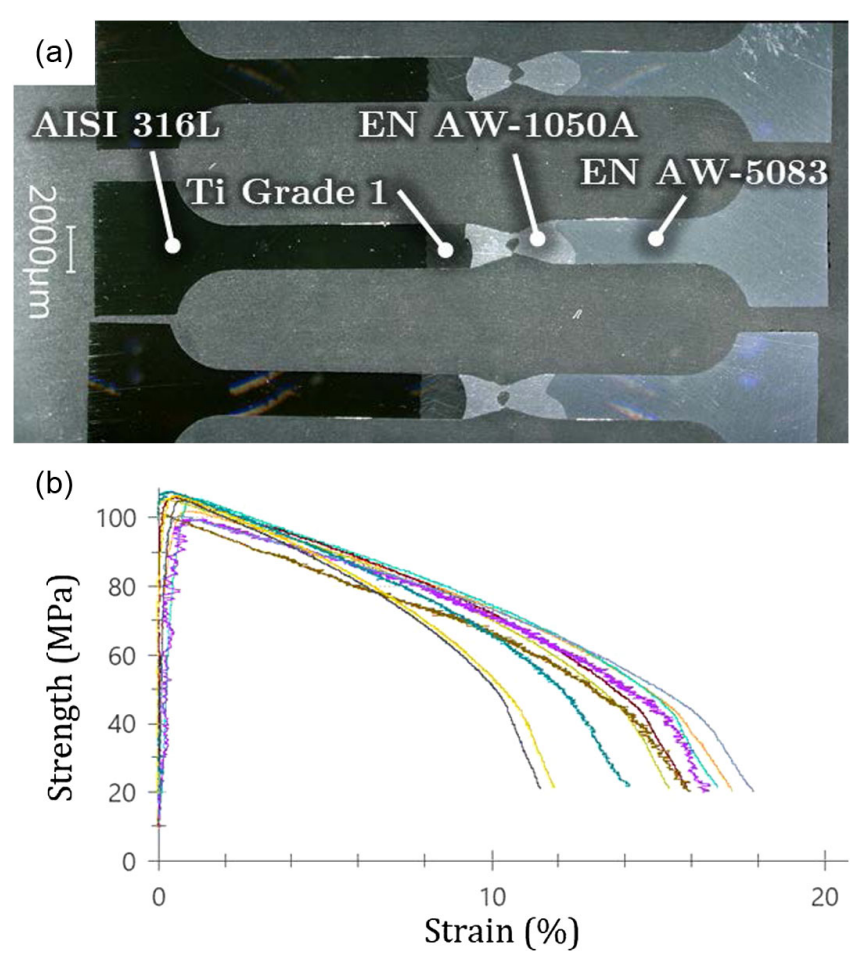

FIG. 8. (a) Bimetallic-transition specimens tested in tension: for all of them, the interfaces between the different materials of the transition (stainless steel AISI 316L, titanium grade 1, aluminum EN AW-1050A H14, aluminum EN AW-5083 H112) were stronger than the weakest base material (pure aluminum EN AW-1050A H14). (b) Stress-strain curves resulting from the tensile tests: the ultimate bond strength is $105 \mathrm{MPa}$.

of the plate from where the final joint is extracted. Regions that appear sound after preliminary dye penetrant and ultrasonic inspections are the best candidates. The final product was selected on this basis, with a final joint thickness of $25 \mathrm{~mm}$, the maximum permitted by assembly and space constraints.

An innovative manufacturing process was developed to accommodate both mechanical and physics requirements of the EAR1 moderator. Shaped like a short cylindrical vessel, the two flat end surfaces, each $3 \mathrm{~mm}$ thick, would exceed the maximum acceptable deformations and stresses induced by the 2.5 bar pressure without additional stiffening elements. The use of a precise deep-milling manufacturing technique offered the possibility to add such stiffeners while preserving the monolithic nature of the part and avoiding welds, which would increase failure risks. Up to $80 \%$ of the material was removed from a solid aluminum disk, with the remaining $20 \%$ shaped to obtain deformations and stresses compliant with the specification. The resulting monolithic center part of the moderator was then welded to the outer housing by electron-beam welding. The outer housing includes the interface with the explosive-bonded joint (Fig. 9).

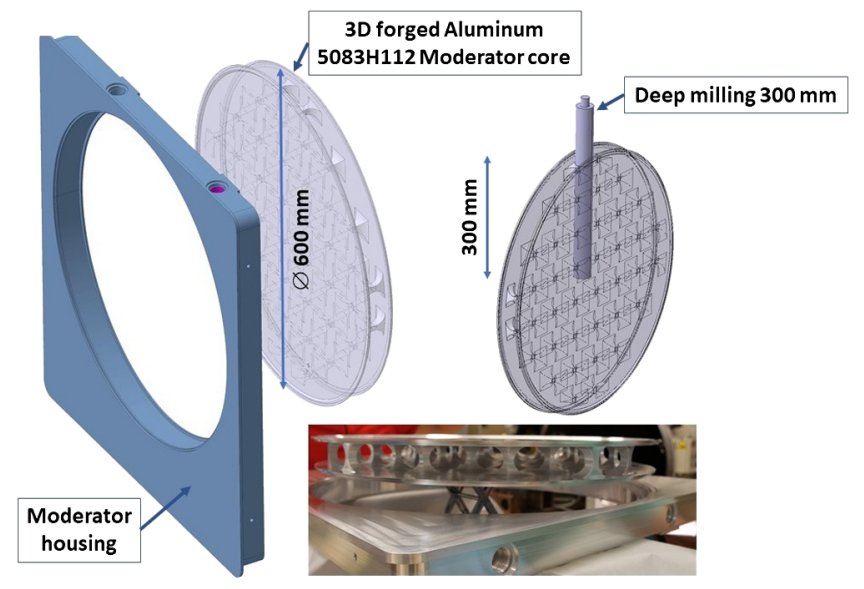

FIG. 9. Schematic view of the deep milling procedure for the EAR1 moderator manufacturing. The central part is entirely machined from a single solid aluminum block (EN AW-5083 H112). It is then bonded to the housing via electron-beam welding.

Special effort was put into the selection process of the bulk material for the disk in terms of homogeneity and grain size, low number of defects, and impurity. The choice fell on 3D forged aluminum EN AW-5083 H112 blocks for its good compliance with the specifications and stability during machining. Compliance with the specifications was checked before machining by dye penetrant and ultrasonic inspections. In addition, the qualification of the electronbeam welding process was carried out on representative samples. To complete the qualification process of the EAR1 moderator, vacuum and pressure tests were successfully carried out to ensure the compliance with pressure vessel safety standards.

\section{NITROGEN COOLING SYSTEM: COMPUTATIONAL FLUID DYNAMICS}

Computational fluid dynamics (CFD) studies were carried out to support and optimize the design of the target. The optimization consisted of maximizing the cooling efficiency (minimizing the maximum steady-state temperature) while minimizing the pressure drop and the locations of high flow velocity inside the target. The CFD calculations also provided input for the thermomechanical analyses (see Sec. V) and for the design of the cooling station (see Sec. VI).

The commercial CFD software ANSYS CFX [28] has been used throughout the studies to model simultaneously the solid (lead slices) and the fluid bodies (nitrogen), and perform conjugate heat transfer calculations. The map of average beam power deposition, calculated with FLUKA Monte Carlo simulations, was imported as a powergeneration boundary condition. The shear stress transport turbulence model [29] was employed to accurately compute the momentum and the thermal boundary layers. 


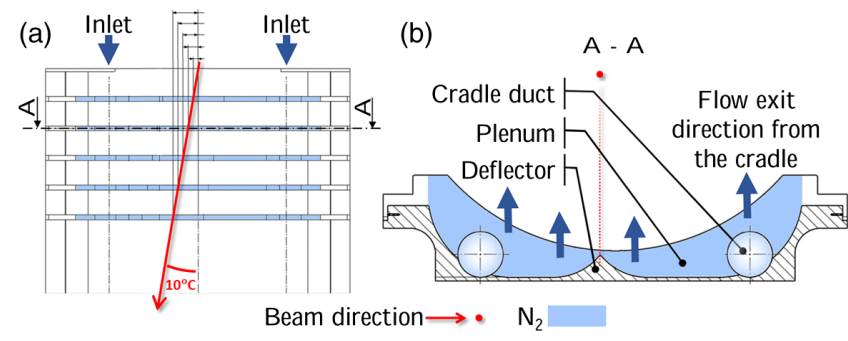

FIG. 10. (a) Top view of the main core assembly (see also Fig. 5). Nitrogen flows through the channels machined in the anticreep plates, perpendicular to the view and toward the observer. The beam does not impact the lead surface perpendicularly, but at a $10^{\circ}$ angle. (b) Cross-cut of the aluminum cradle through the second row of channels, showing the plenum volume and the geometry used to guide the flow into the channels.

\section{A. Design and performance optimization}

The CFD design optimization encompassed three main components: inlet and outlet ducts of the target vessel, cradle, and anticreep plates.

The optimization was initially focused on tuning the number of inlets and outlets, their position, and dimensions. The final configuration presents the best compromise between the target pressure drop and a balanced distribution of nitrogen, while complying with the space constraints of the assembly.

The cradle was designed to evenly distribute the nitrogen flow from the inlets to the channels between the lead slices. Large plenum volumes, as shown in Fig. 10, induce a deceleration of the fast flowing nitrogen, while their curved geometry inhibits flow separation at the walls due to the adverse pressure gradient, typical of a sudden expansion. As shown in Fig. 10, the incident beam axis forms a $10^{\circ}$ angle with the target to reduce the EAR1 background caused by $\gamma$-rays and high-energy charged particles [8]. The beam is sufficiently diverging so that a dedicated dump is not required downstream of the target in addition to the iron and marble already present around the target area (see Sec. VII). The cradle design is complemented with flow deflectors aligned with the beam axis to focus the cooling flow on the hottest regions of the lead surface.

The anticreep plates drive the nitrogen over the lead surface while containing the creep deformation of the material. The distribution of flow rate among the channels is optimized by adding wedge-shaped obstructions in the channels that are located farther from the beam, as schematically shown in Figs. 11 and 12. The geometry of these obstructing wedges was carefully designed to minimize pressure losses and flow disturbances.

\section{B. Cooling performance}

The cooling performance is presented for four operational cases, summarized in Table II. Cases A and B reflect the two normal operational limits of the cooling station,

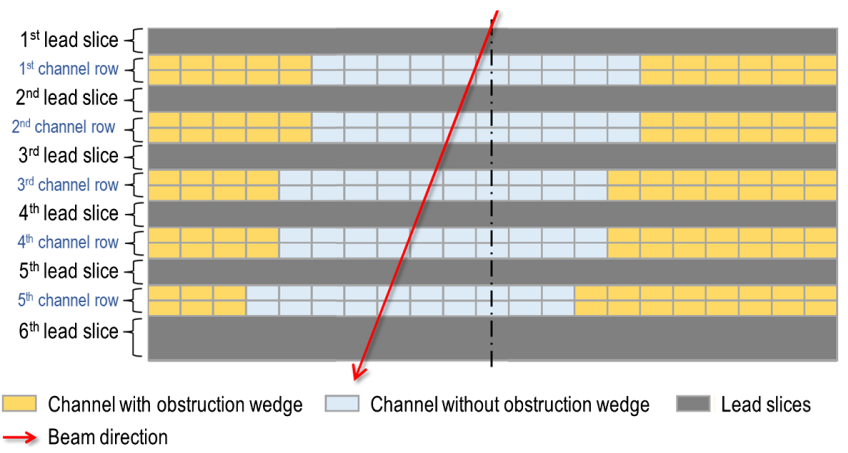

FIG. 11. Schematic view of the main core assembly (see also Fig. 5) showing, highlighted in yellow, the channels with wedgeshaped obstructions. The obstructions partially restrict the flow in the channels located farther from the beam axis, increasing the flow rate on the regions of lead surface directly impacted by the beam.

while cases $\mathrm{C}$ and $\mathrm{D}$ assess the cooling performance when some of the cooling channels are obstructed by lead due to creep deformation. The cases $\mathrm{C}$ and $\mathrm{D}$ are defined by considering no flow nor heat transfer in the channels that are adjacent to the lead surfaces where the highest temperature values are expected. The channels simulated as obstructed are the ones closest to the beam line, on both faces of the second slice and on the downstream face of the sixth slice (according to the nomenclature in Fig. 11). For each of these faces, three channels are considered obstructed in scenario C, while five channels are considered obstructed in scenario D. Given the expected creep deformations discussed in Sec. V, these two cases represent rather conservative degraded scenarios.

Considering a beam average power of $5.4 \mathrm{~kW}(2.7 \mathrm{~kW}$ absorbed by the lead slices) and a beam size of $15 \mathrm{~mm}$ (rms), the maximum steady-state temperature in each slice is reported in Fig. 13, and it appears correlated to the heat absorbed by each slice. The first and sixth slices are an

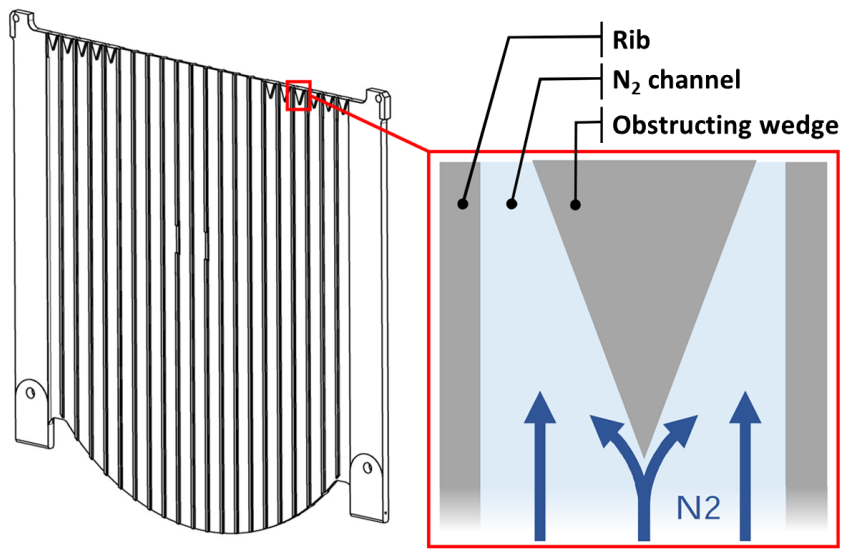

FIG. 12. Example of an anticreep plate and detail of the wedgeshaped obstructions. The obstructing wedges increase the pressure drop but help deliver higher flow rate on the regions of lead surface directly impacted by the beam. 
TABLE II. Normal and degraded scenarios simulated for cooling performance assessment.

\begin{tabular}{lcc}
\hline \hline Case & $\mathrm{n}^{\circ}$ clogged channels & Volume \\
\hline A & 0 & 800 \\
B & 0 & 1000 \\
C & 3 & 800 \\
D & 5 & 800 \\
\hline \hline
\end{tabular}

exception: the first slice absorbs the lowest amount of heat without being the coldest one, while the sixth slice absorbs the highest amount of heat without being the hottest one. This is due to the fact that they are cooled only on one of the two faces.

The maximum steady-state temperature values occur in the second and sixth slices, ranging between $85-89^{\circ} \mathrm{C}$ and $83-90^{\circ} \mathrm{C}$, respectively, and depending on the nitrogen flow. These values are likely to increase if substantial creep occurs where lead is subjected to higher temperature and stress values, with the second slice experiencing the highest increase ( $25 \%$ for case D).

Within each slice, the temperature is highest close to the beam axis, as shown in Fig. 14. For the downstream and upstream face of the second and sixth slices, respectively, the temperature profile along the horizontal at the height of the beam axis is shown in Fig. 15. The average velocity of the nitrogen flow in the corresponding channels is also represented: the speed is higher in the channels without obstructing wedges, which translates into a higher heat transfer coefficient (HTC) where most of the beam power is absorbed.

The HTC values were estimated using the Gnielinski formulation with entrance length correction [30], using the velocity and surface temperature values obtained from the CFD simulations, and the fluid properties at the bulk temperature of nitrogen. The HTC values computed

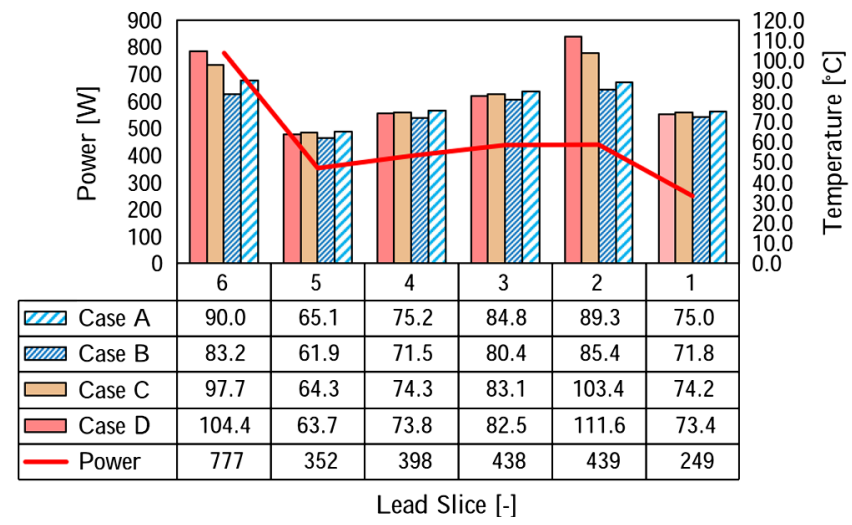

FIG. 13. Maximum steady-state temperature in each lead slice and scenario described in Table II, considering an average beam power of $5.4 \mathrm{~kW}$ and a beam size of $15 \mathrm{~mm}(\mathrm{rms})$. The highest temperature is reached in the second slice, followed by the sixth slice.

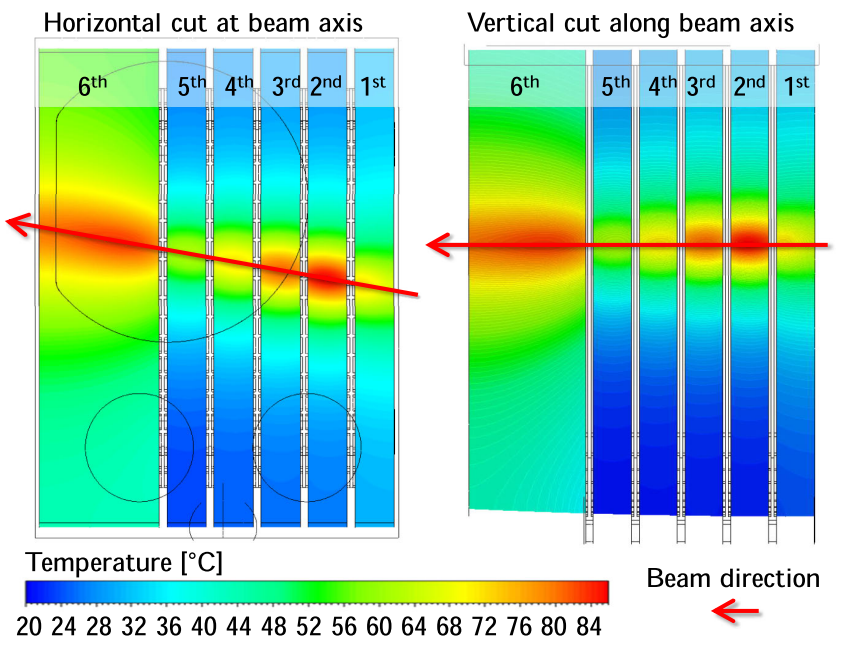

FIG. 14. Steady-state temperature distribution in the lead slices, cross sections intersecting the beam axis. The beam axis is not orthogonal to the lead surface, but tilted by $10^{\circ}$ in the horizontal plane to reduce the EAR1 background caused by $\gamma$-rays and highenergy charged particles.

analytically at beam height exceed the ones from the CFD simulations by $10-30 \%$, which is a reasonable match given the complexity of the geometry.

The pressure drop estimated by simulations and the peak value of velocity in the target for the two operational cases are summarized in Table III.

The pressure drop in the target is expected to be between 4 and $7 \mathrm{kPa}$ depending on the flow. A detailed analytical estimation of the pressure drop in the target vessel was calculated via the loss coefficient method using coefficients from [31-33], and a good agreement (difference lower than $10 \%$ ) was found when compared to simulations. The blockage of cooling channels due to creep, as in case D, results in an increase of $6 \%$ in pressure drop, which is well within the range in which the cooling station can operate.

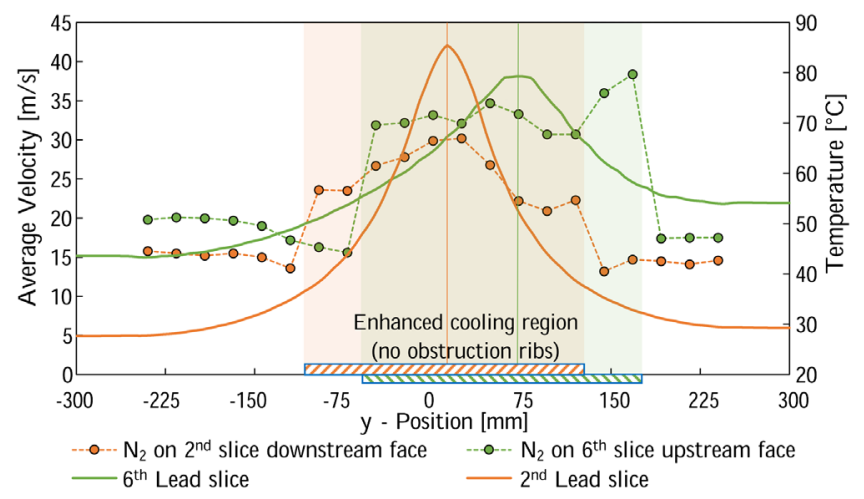

FIG. 15. Steady-state temperature profile along the horizontal at the height of the beam axis, for the downstream and upstream face of the second and sixth slices, and average nitrogen velocity in the corresponding cooling channels. 
TABLE III. Nitrogen pressure drop in the target and peak velocity values for the four scenarios described in Table II.

\begin{tabular}{lrrrr}
\hline \hline & A & B & C & D \\
\hline Pressure drop $(\mathrm{kPa})$ & 4.7 & 7.0 & 4.8 & 5.0 \\
Maximum velocity $(\mathrm{m} / \mathrm{s})$ & 77.2 & 89.5 & & \\
\hline \hline
\end{tabular}

The analysis also shows that the nitrogen velocities in the target are below Mach 0.3, thus the flow can be considered incompressible everywhere, with the highest velocities occurring at the bend of the vessel inlets. Inside the target vessel, specifically in the cradle ducts, the nitrogen flows relatively fast, decelerating as it flows into the plenums along the ducts. The analysis results reveal that velocities up to $65 \mathrm{~m} / \mathrm{s}$ are expected to occur at the entrance of a few channels due to the apparent cross section reduction and flow separation at the entrance of the channels. The nitrogen flowing through the narrow sections beside the obstruction wedges can reach velocities between 70 and $87 \mathrm{~m} / \mathrm{s}$ for cases $\mathrm{A}$ and $\mathrm{B}$, respectively; however, the velocities at the beam impinging spots are below $40 \mathrm{~m} / \mathrm{s}$. The highest velocity values, besides taking place in limited and localized areas over colder lead surfaces, are within the acceptable threshold value to avoid erosion of $110 \mathrm{~m} / \mathrm{s}$ (according to [34]).

\section{THERMOMECHANICAL ASSESSMENT OF THE LEAD CORE}

The time evolution of temperature, stress, and strain in the target were estimated by means of CFD and FEM analyses with ANSYS and LS-DYNA [28].

\section{A. Thermal analyses}

The temperature dependence of every material property has been included in the analyses. The reference sources for the thermal properties are [35-37].

The most conservative assumption that can be made regarding the beam load is that all of the six pulses hit the target consecutively with the minimum period of $1.2 \mathrm{~s}$. The six pulses are then followed by a cooldown of $30 \mathrm{~s}$, totaling a cycle of $36 \mathrm{~s}$ (hereinafter referred to as supercycle). The load boundary condition for the thermal analyses is a power generation field in the target, resulting from the interaction between beam and target and obtained by means of FLUKA Monte Carlo simulations.

The cooling effect of nitrogen is modeled by a convective boundary condition, where the heat transfer coefficient (HTC) field was imported from the CFD simulations described in Sec. IV. The average HTC is $63.8 \mathrm{~W} \mathrm{~m}^{-2} \mathrm{~K}^{-1}$, but the flow is optimized to be faster at the beam impinging spot, where the HTC reaches a value of $130 \mathrm{~W} \mathrm{~m}^{-2} \mathrm{~K}^{-1}$.

The second lead slice crossed by the beam is subject to the highest energy deposition and temperature. The results of thermal simulations for this slice are shown in Figs. 16

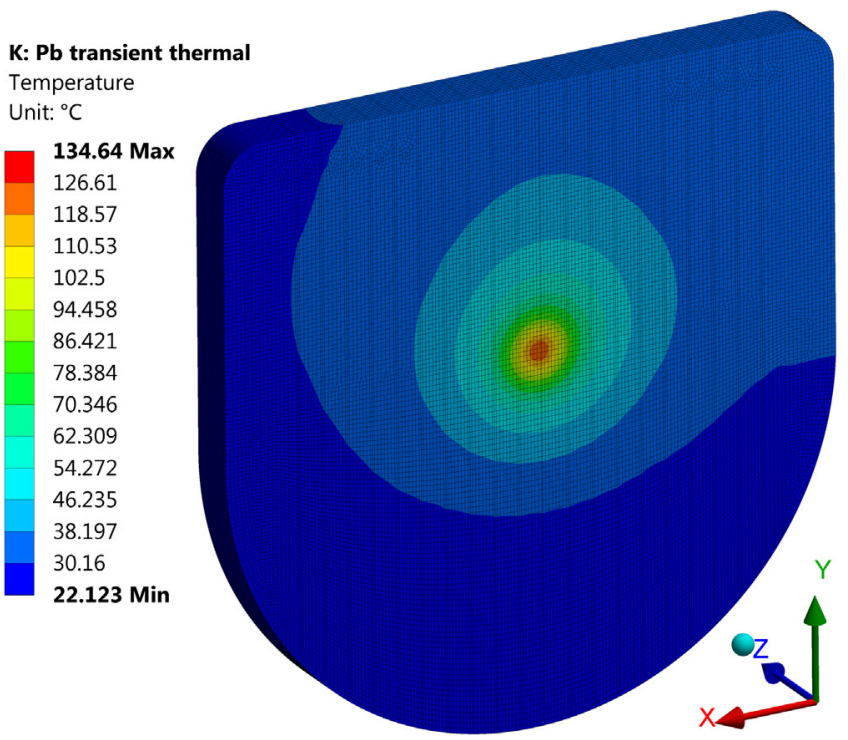

FIG. 16. Temperature map, in the second lead slice crossed by the beam, at the instant of peak temperature. The peak temperature is equal to $135^{\circ} \mathrm{C}$.

and 17: Fig. 16 shows the temperature field at the instant of peak temperature, while Fig. 17 shows the plot of maximum temperature vs time during three 36-s supercycles, once periodic steady state is reached. The peak temperature is $135^{\circ} \mathrm{C}$, safely lower than the melting point of lead $\left(327^{\circ} \mathrm{C}\right)$ but high enough to significantly decrease strength and promote creep. Figure 17 also shows the benefits of a change of optics, if feasible: a larger beam size ( $25 \mathrm{~mm} \mathrm{rms})$ lowers the peak temperature to $96^{\circ} \mathrm{C}$.

A series of six radiation-hard thermocouples have been placed inside the target, directly in contact with the lead slices. Although they can provide benchmarks for the thermal simulations and feedback on the status of the target core, they are not essential for the target operation in case they fail prematurely.

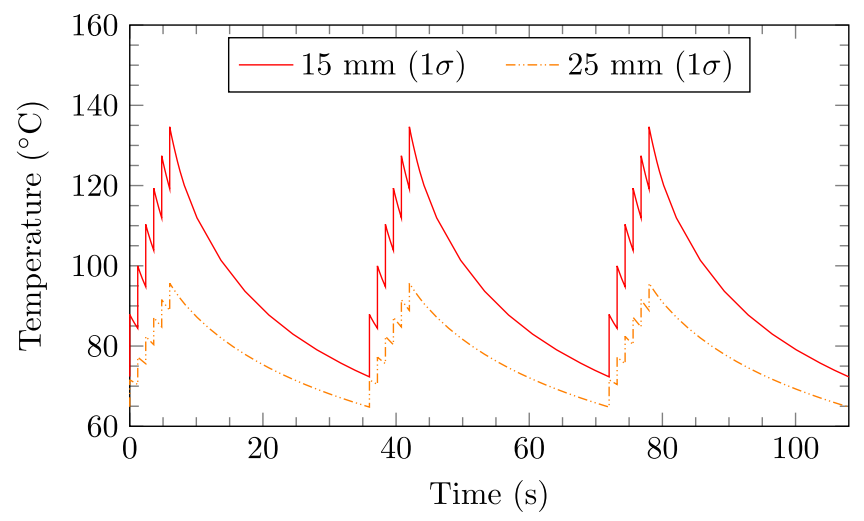

FIG. 17. Maximum temperature in the target lead core during three 36-s supercycles once periodic steady state is reached, with beam size of 15 and $25 \mathrm{~mm}$ (rms). 


\section{B. Stress analyses}

The target is subject to mechanical stress due to two effects, both included in the analyses: quasistatic stresses and dynamic stresses. Quasistatic stresses are induced by heat from the absorbed beam power in the target, which provokes temperature and thermal expansion gradients. Furthermore, each beam pulse is absorbed in $7 \mathrm{~ns}(\mathrm{rms})$, provoking an impulsive temperature rise and consequent thermal expansion, which causes the propagation of stress waves and induces dynamic stresses.

The properties used for the structural analyses are taken from [38-40]. Two constitutive models were used to model plasticity: pure isotropic hardening (without Bauschinger effect), and pure kinematic hardening (with Bauschinger effect) [41]. Material characterization activities were carried out to develop a nonlinear kinematic hardening model for plasticity of pure lead. The details of this research will be reported in a dedicated publication.

Figures 18 and 19 show some of the results of the structural simulations featuring the pure kinematic hardening model. Figure 18 shows the von Mises equivalent stress map during the stress-wave propagation stage. Figure 19 shows the oscillations, due to dynamic effects, of the von Mises equivalent stress after the sixth (and last) pulse in a supercycle. The peak value of von Mises stress is 2.6 $\mathrm{MPa}$, while pressure and maximum principal stress reach $80 \mathrm{MPa}$ : the hydrostatic component of stress is dominant. The stress level is quite high if compared to the strength of pure lead (plastic flow begins below $1 \mathrm{MPa}$ ); thus, a target prototype was tested under beam irradiation in the HiRadMat facility at CERN [42]. The outcome of the

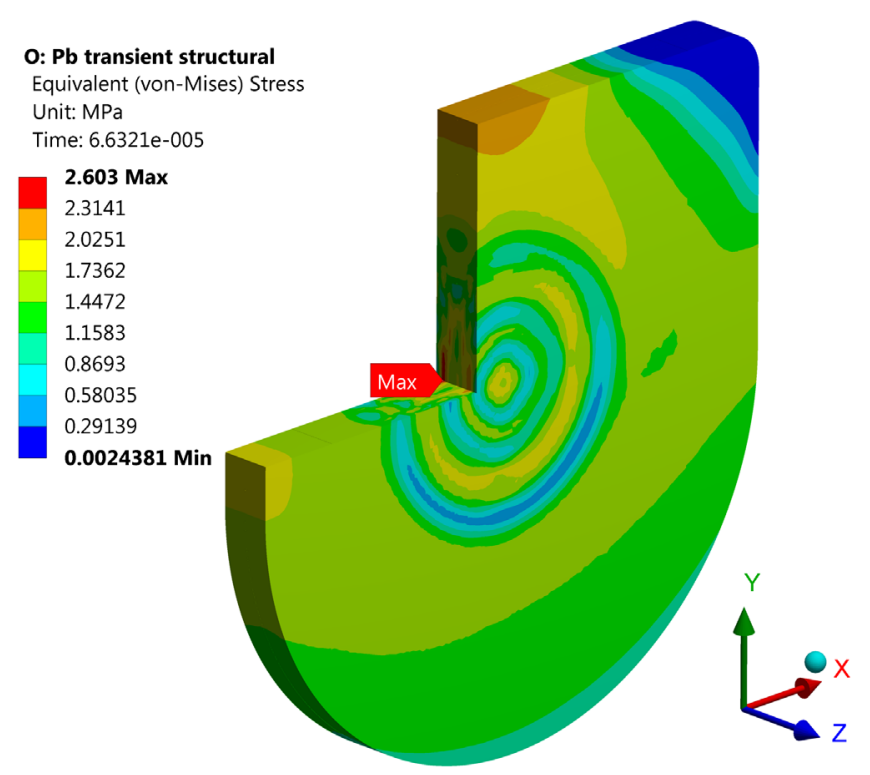

FIG. 18. Peak von Mises equivalent stress in the target lead core during propagation of stress waves. The stress waves start propagating radially from the area of impact on the proton beam axis.

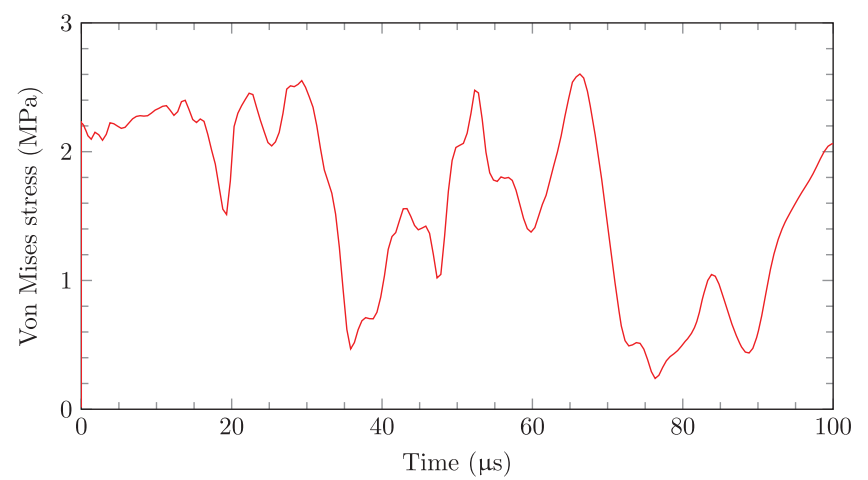

FIG. 19. Von Mises stress vs time in the target lead core after the sixth (and last) pulse of a supercycle. The oscillations are provoked by the instantaneous temperature spike due to heat dissipation of the beam pulse.

beam irradiation test was positive as no defects and internal voids were observed inside the material by neutron tomography inspections [8]. Further details of this beam irradiation test will be presented in a separate publication.

\section{Creep analyses}

Pure lead is strongly affected by creep, i.e., plastic flow of material with time, especially at the temperature reached in the $\mathrm{n}_{-} \mathrm{TOF}$ target $\left(135^{\circ} \mathrm{C}\right.$ maximum). Creep phenomena could induce lead to flow into some of the cooling channels, obstructing them and reducing the cooling efficiency. The creep strain rate for each level of temperature and stress is plotted in the deformation-mechanism maps [40]. A constitutive model able to reproduce lead creep over all the stress and temperature ranges of interest for the n_TOF target is not readily available in ANSYs; thus, a new model was coded as user programmable feature (UPF). The new model consists of a series of piecewise functions, each composed of multiple power laws (of the kind $\dot{\epsilon}=c \sigma^{n}$ ) with different coefficients: each piecewise function reproduces the deformation-mechanism maps for a single temperature; the creep strain rates for intermediate temperatures are obtained by logarithmic interpolation.

The sixth (and last) lead slice intersected by the beam is the thickest $(15 \mathrm{~cm})$ and is subjected to the largest creep deformations. A simulation, featuring the new creep constitutive model, was performed to estimate the maximum penetration, due to creep, of the lead slice into the cooling channels. The loads considered in the analysis are the weight of the slices and the temperature field at the instant of peak temperature. The temperature field is conservatively assumed to be constantly applied for $2 \times 10^{8} \mathrm{~s}$ (approximately 6 years and 4 months of continuous operation, twice the target lifetime). The resulting displacements are shown in Fig. 20: the maximum penetration is $0.64 \mathrm{~mm}$, whereas the channel depth is $3 \mathrm{~mm}$.

As described in Sec. IV, degraded scenarios including the possibility of obstructed channels were considered in CFD 
Deformation along the $\mathrm{Z}$ axis $(\mathrm{mm})$

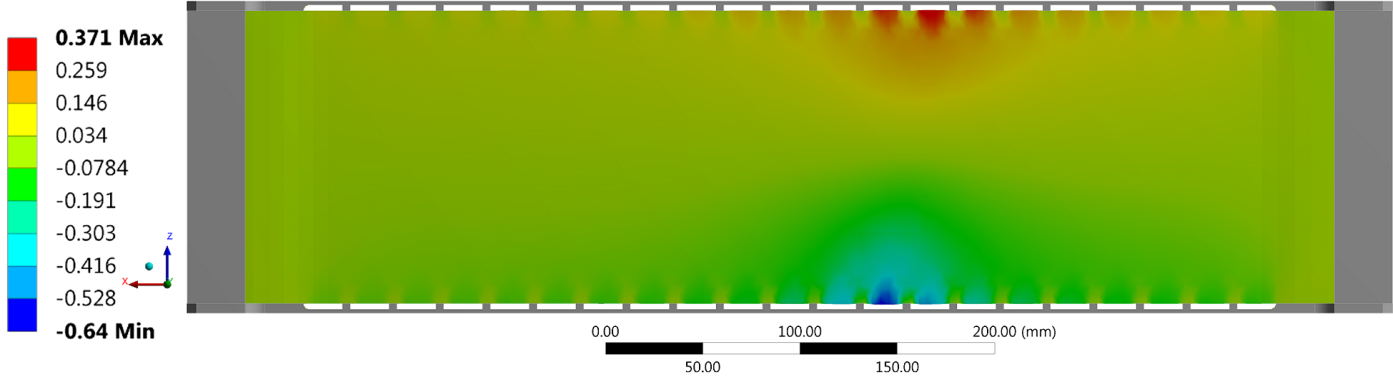

FIG. 20. Penetration, due to creep, of the 15-cm thick lead slice into the cooling channels (view from the top, cross-section cut through the point of maximum penetration). The gray parts are the aluminum (EN AW-6082 T6) anticreep plates with the cooling channels. The color map shows the maximum projected displacements after $2 \times 10^{8} \mathrm{~s}$ (approximately 6 years and 4 months of continuous operation, twice the target lifetime).

simulations. The results of this analysis show that the target operation would not be compromised: the lead slice would be subject to a maximum peak temperature of $160^{\circ} \mathrm{C}$, which is considered acceptable for the degraded scenario under examination.

\section{DESIGN OF THE NITROGEN COOLING STATION}

The nitrogen gas for the target cooling system is produced by a nitrogen generator, recirculated in the cooling circuit, and cooled by chilled water. The design requirements of the nitrogen cooling system are summarized in Table IV. The nitrogen flow is filtered by high efficiency particulate air (HEPA) and active carbon filters to capture particles and volatile compounds released in the nitrogen stream. The part of the cooling system between the target vessel and the filter casing containing the filters is enclosed in a sealed room under dynamic confinement: an extractor ensures that the pressure in the sealed room is lower than the surrounding environment. In case of a leak of activated nitrogen from the filter casing, the radioactive gas is therefore contained in the sealed room and extracted to a dedicated ventilation system in the target tunnel area. The maximum leak rate in the unconfined part of the circuit that has been considered acceptable after radiation protection studies (see Sec. VII) is $5 \mathrm{~L} / \mathrm{h}$.

The cooling station supplies nitrogen gas to cool the target lead slices via AISI 304L stainless steel pipes. The main elements of the cooling station are shown in Fig. 21.

TABLE IV. Nitrogen cooling station: cooling requirements.

\begin{tabular}{lc}
\hline \hline Quantity & Value \\
\hline Cooling power & $2.6 \mathrm{~kW}$ \\
Nominal flow rate & $780 \mathrm{Nm}^{3} / \mathrm{h}$ \\
Pressure drop & $30 \mathrm{mbar}$ \\
Gas supply temperature & $20 \pm 2^{\circ} \mathrm{C}$ \\
Maximum pressure & $500 \mathrm{mbar}$ \\
\hline \hline
\end{tabular}

The gas compressor (blower) is a multistage centrifugal compressor with a flow rate of $1000 \mathrm{Nm}^{3} / \mathrm{h}$ and a pressure rise of 285 mbar. It integrates features to minimize gas leaks such as magnetic coupling between compressor shaft and motor, silicone groove O-rings between casing discs, and EPDM (ethylene propylene diene monomer rubber) seals at all bolted flanges. The $29-\mathrm{kW}$ heat exchanger is installed downstream of the blower to cool the hot nitrogen gas down to $20^{\circ} \mathrm{C}$ via chilled water. It is of tubular type to minimize the pressure drop and has tubes arranged in a horizontal configuration. The nitrogen stream is filtered by a HEPA filter upstream of the target and by a double-stage nucleargrade HEPA plus active-carbon filter downstream of the target. Class 3 (ISO 10648-2) gas-tight filter casings host all of the filters. The casing design allows the filter status to be monitored and the filters to be replaced without contact with nitrogen. The HEPA filters capture particles and aerosols with an efficiency greater than $99.98 \%$ for a minimum particle size of $0.15 \mu \mathrm{m}$. The active carbon filter captures any volatile compound released in the nitrogen gas stream. A gas-analysis system based on quadrupole mass spectrometry analyzes continuously the gas composition upstream and downstream of the double-stage filter casing with the HEPA and the active carbon filters. As previously mentioned, the filters are installed inside a sealed room kept in dynamic confinement via an extraction fan.

\section{RADIATION PROTECTION CONSIDERATIONS}

The radiation protection (RP) implications of the target were thoroughly analyzed during its design phase; the outcomes of this analysis, which also took into account the return on experience from ten years of operation of Target \#2, contributed to the optimization of the target design. The main RP aspects addressed in the target design study are: stray radiation in accessible areas and compliance with CERN's radiological area classification; critical aspects of the new cooling system; air activation in the target area 

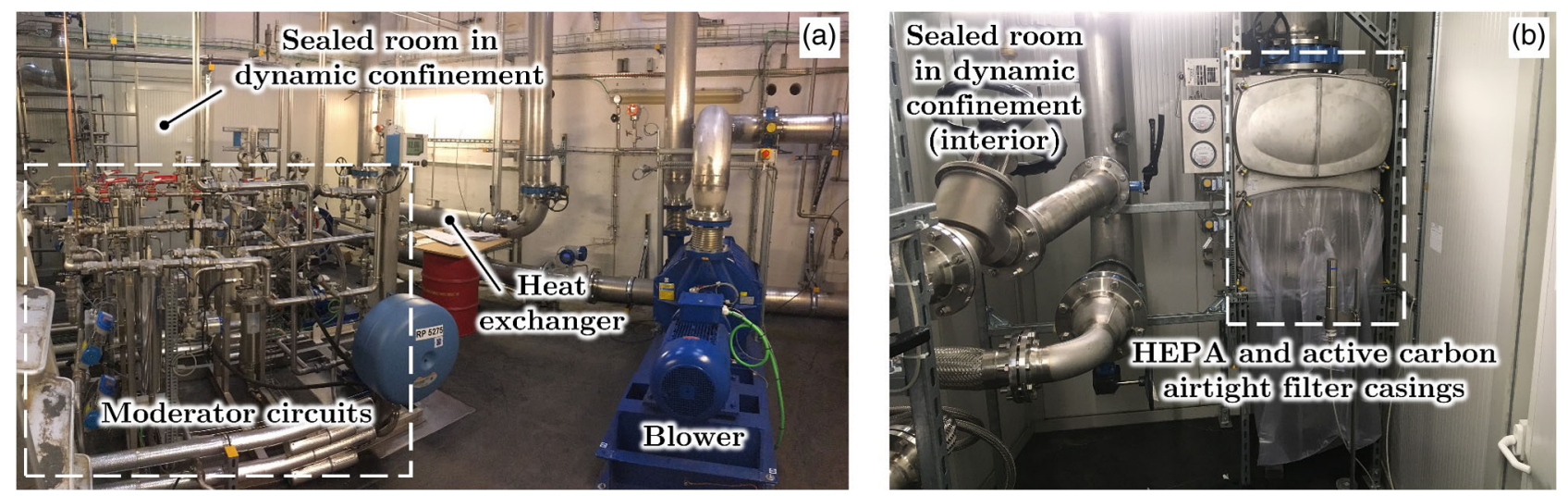

FIG. 21. (a) Main components of the cooling and moderator station. The cooling nitrogen is compressed in the blower, cooled down in the heat exchanger, and filtered upstream and downstream of the target. The station also includes the two separate moderator circuits for EAR1 and EAR2, which can work independently with demineralized water or borated water. The filters are located inside an airtight room in dynamic confinement. (b) Photo inside the airtight room in dynamic confinement. The HEPA and active-carbon filter capture particles and volatile compounds in the nitrogen stream.

and atmospheric releases; radioactive waste considerations in view of the target final disposal at the end of its lifetime.

Along with the target, the target shielding was also upgraded. The Target \#2 shielding, composed of fixed concrete blocks with a maximum thickness of $200 \mathrm{~cm}$, has been replaced with a new mobile version. The new shielding is composed of a first layer of $40-\mathrm{cm}$ thick iron followed by $80 \mathrm{~cm}$ of concrete and finally a $20-\mathrm{cm}$ layer of marble. The shielding wall has two main goals: to limit air activation in the target area during beam operation and subsequent releases into the environment (see Sec. VII C) and to reduce the residual activation levels in the area during access. The new mobile shielding provides direct access to the target and enhances the potential applications of the facility (e.g., to perform irradiation of material samples in the proximity of the target [43]). Several openings are present in the shielding to permit the future installation of a pneumatic system to transport radioactive samples and to access the target with endoscopes and radiation probes. The shielding plays a major role in ensuring adequate radiation protection and, therefore, it was studied and optimized by means of FLUKA simulations (Fig. 22).

\section{A. Stray radiation}

As already mentioned in Sec. II A, Target \#3 provides, when compared to Target \#2, a neutron fluence towards EAR2 twice as high in the energy range $100 \mathrm{keV}-$ $200 \mathrm{MeV}$; the locations of the n_TOF facility that could be impacted by the resulting stray radiation are the ones surrounding the 20-m vertical beam line, i.e., EAR2 and ISR8 (the eighth octant of the former CERN intersecting storage ring, Fig. 23).

The ISR8 area is shielded with concrete blocks and houses the cooling station and a space for storage.
FLUKA simulations were performed to assess the ambient dose equivalent, $H^{*}(10)$. Figure 24 shows the prompt $\mathrm{H}^{*}(10)$ rate in the ISR8 area normalized to the average beam intensity of $1.67 \times 10^{12} \mathrm{p}^{+} / \mathrm{s}$ : the worst location in terms of radiation exposure is inside the $n_{-}$TOF storage
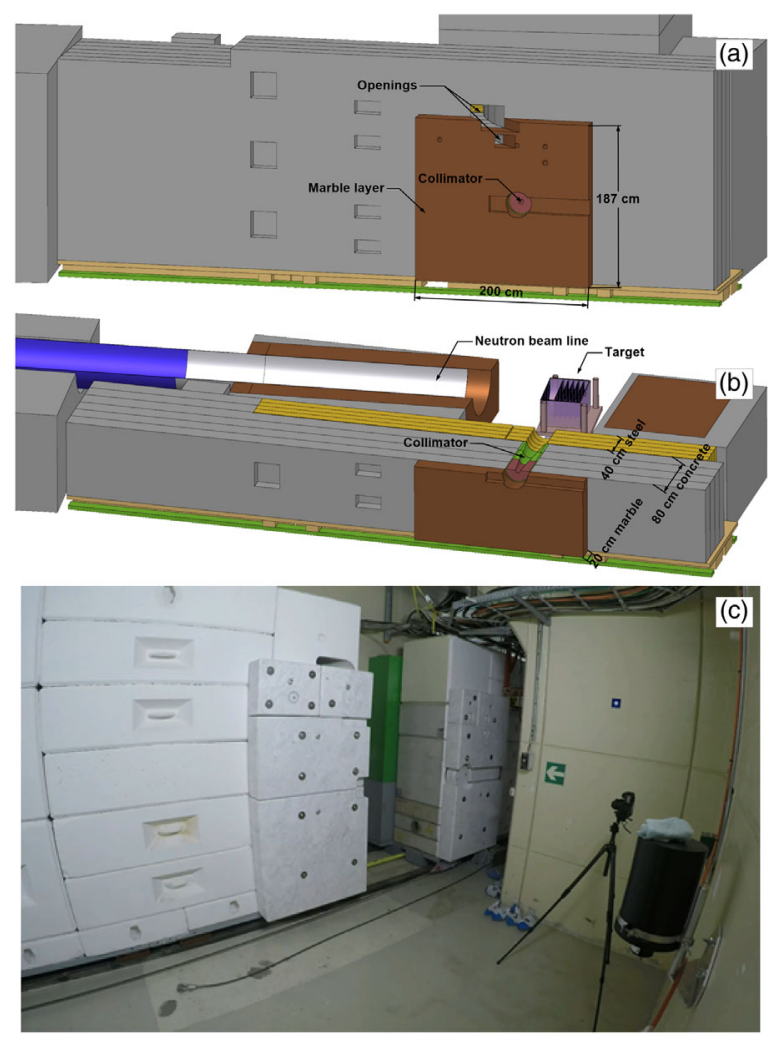

FIG. 22. (a) 3D view of the FLUKA geometry of the new shielding. (b) 3D cross-sectional view inside the shielding wall. (c) Photo of the shielding in "open" position: it can be moved on rails to access the target area. 


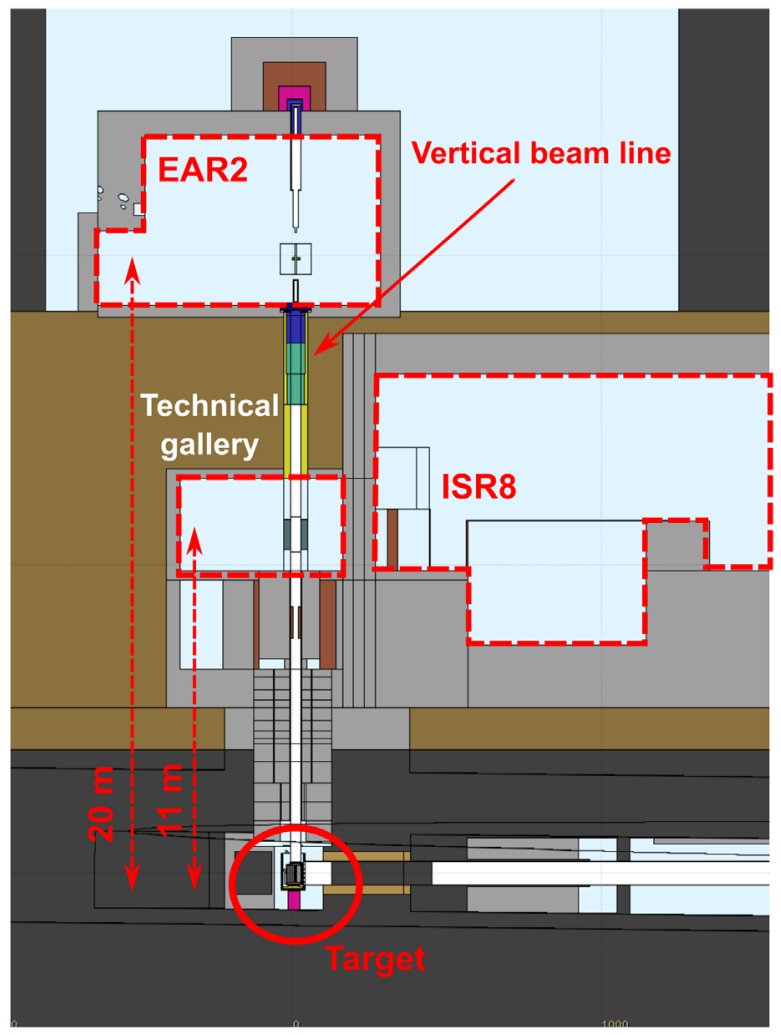

FIG. 23. FLUKA geometry: side view of the vertical beam line. The most important locations impacted by stray radiation are the experimental area EAR2 and the ISR8 area.

area close to the shielding wall. The $\mathrm{H}^{*}(10)$ is, however, always lower than $0.3 \mu \mathrm{Sv} / \mathrm{h}$, well below the applicable limit. In addition, the simulated $\mathrm{H}^{*}(10)$ and the integrated number of protons delivered to the target in a year were used to estimate the exposure of personnel working in ISR8 (400 hours per year considering ISR8 a low-occupancy area). Figure 25 shows that the annual exposure of personnel in ISR8 is always below the CERN optimization

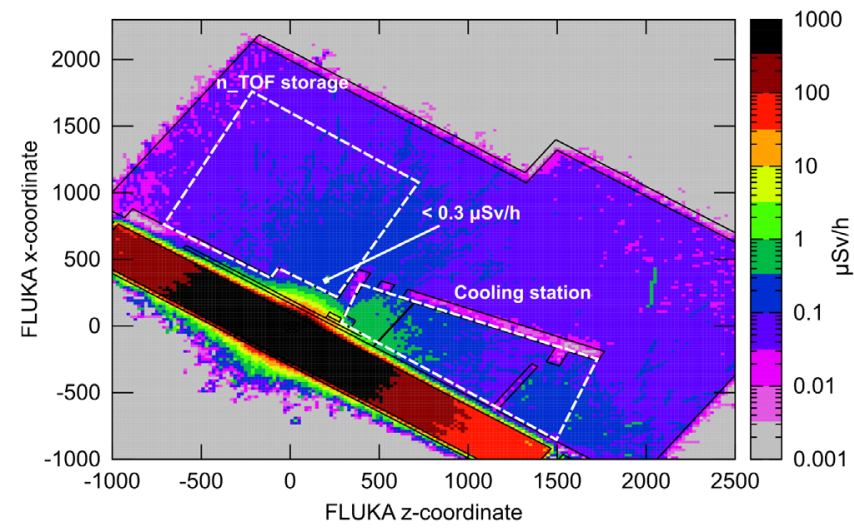

FIG. 24. Prompt $\mathrm{H}^{*}(10)$ rate in ISR8 for the maximum average beam intensity of $1.67 \times 10^{12} \mathrm{p}^{+} / \mathrm{s}$. The highest radiation exposure is in the $\mathrm{n}_{-} \mathrm{TOF}$ storage area, but still below the applicable limit.

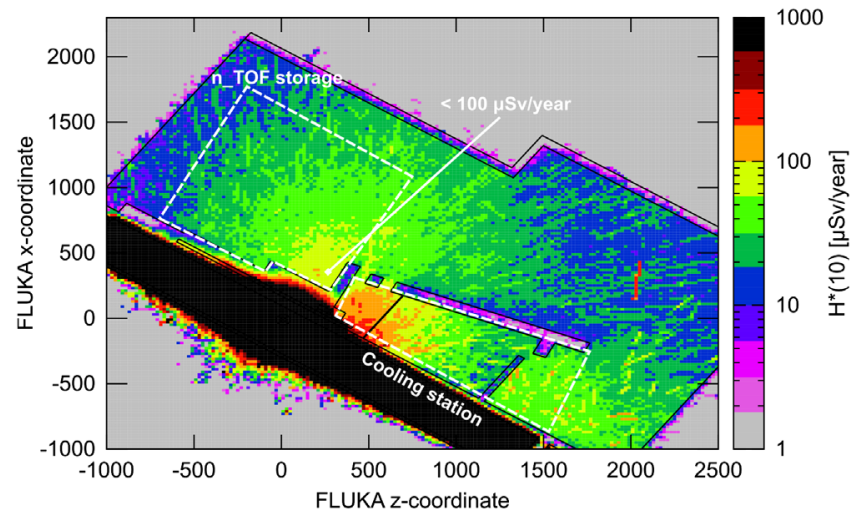

FIG. 25. Annual ambient radiation dose equivalent $H^{*}(10)$ in ISR8 for 400 hours of exposure and $2.5 \times 10^{19}$ protons on target. The annual exposure is always below the limit of $100 \mu \mathrm{Sv}$.

objective of $100 \mu \mathrm{Sv}$. At the time of the construction of the vertical beam line in 2014, the shielding of EAR2 was conservatively designed to take into account a possible increase of the neutron fluence up to a factor of 3 . Calculations showed that the new neutron fluence is within this threshold.

\section{B. Cooling circuit}

From an RP standpoint, one of the critical aspects of the operation of Target \#2 was the direct contact between the cooling water and the lead core; due to erosion-corrosion and out-diffusion effects, lead spallation products migrated from the target into the cooling water. These radionuclides include not only $\gamma$-emitters like $\mathrm{Hg}-194, \mathrm{Au}-195$, and Bi-207, but also $\alpha$-emitters like Gd-148, Po-208, Po-209, and Po-210. The cooling circuit is equipped with cartridges to trap some of these components and reduce the contamination in the circuit. As a consequence, the cartridges represented radiation hot spots and were an important source of external exposure during inspections or maintenance activities in the cooling station; in addition, the presence of contamination in the circuit increased the radiological risk during intervention.

The new nitrogen cooling circuit coupled with HEPA and active carbon filters reduces the presence of lead spallation products and increases the radiological safety during maintenance activities. As described in Sec. VI, the room housing the filters is under dynamic confinement and the extracted air is directed into the target area from where it is released outside, thanks to the preexisting ventilation and radiation monitoring system (see also Sec. VII C). Activation and contamination levels of the nitrogen circuit are monitored by a dedicated beta-radiation detector.

\section{Air activation in the target area and environmental releases}

The air surrounding the target area becomes activated due to high-energy hadron interactions. Short-lived 
TABLE V. Annual released activity, $A_{\text {rel }}$, for the radionuclides mostly contributing to the effective dose for radioactive emission.

\begin{tabular}{lcccc}
\hline \hline & & \multicolumn{2}{c}{$A_{\text {rel }}(\mathrm{Bq} /$ year $)$} & \\
\cline { 3 - 4 } Nuclide & $\mathrm{t}_{1 / 2}$ & Target \#2 & Target \#3 & $\frac{\text { Target \#3 }}{\text { Target \#2 }}$ \\
\hline${ }^{11} \mathrm{C}$ & $20.4 \mathrm{~min}$ & $3.69 \times 10^{11}$ & $4.31 \times 10^{11}$ & 1.17 \\
${ }^{13} \mathrm{~N}$ & $10.0 \mathrm{~min}$ & $9.40 \times 10^{11}$ & $1.15 \times 10^{12}$ & 1.22 \\
${ }^{15} \mathrm{O}$ & $2.0 \mathrm{~min}$ & $4.13 \times 10^{11}$ & $4.96 \times 10^{11}$ & 1.20 \\
${ }^{41} \mathrm{Ar}$ & $1.8 \mathrm{~h}$ & $2.83 \times 10^{12}$ & $1.77 \times 10^{12}$ & 0.63 \\
\hline \hline
\end{tabular}

positron emitters, like ${ }^{11} \mathrm{C},{ }^{13} \mathrm{~N},{ }^{14,15} \mathrm{O}$, are produced in oxygen and nitrogen by spallation reactions. In addition, ${ }^{41} \mathrm{Ar}$ is generated by thermal neutron capture in the natural argon in air. These radionuclides are the main concern when evaluating the environmental impact of radioactive releases.

The n_TOF target area is dynamically confined from the adjacent zones; the dynamic confinement is guaranteed by extracting air from the target area at a rate of about $300 \mathrm{~m}^{3} / \mathrm{h}$ during beam operation, and up to $500 \mathrm{~m}^{3} / \mathrm{h}$ in case of access. After a filtering stage and radiation monitoring, the air is released into the environment. During the operation of Target \#2, the effective dose due to environmental releases from the n_TOF facility was, on average, about $0.6 \mu \mathrm{Sv}$ per year, well below the CERN optimization objective of $10 \mu \mathrm{Sv}$ per year.

Following the recent modifications implemented in the target area, i.e., the design and installation of the new target and the new mobile shielding, air activation as well as the impact of environmental releases to the reference population group were assessed and compared with the ones of Target \#2. The particle spectral fluence for neutrons, charged pions, protons, and photons were simulated by FLUKA simulation package. Then, using ACTIWIZ (an analytical code developed at CERN [44]), the particle spectral fluences were folded with production cross sections for air to obtain the radionuclide production yields per primary proton impinging on the target. The activity released into the atmosphere all along the irradiation, $A_{\text {rel }, i}$, of a given radionuclide $i$ can be calculated using Eq. (1) [45]:

$$
A_{\mathrm{rel}, i}=Y_{i} I \frac{\lambda_{i}}{\lambda_{i, \mathrm{eff}}} \frac{Q}{V}\left(t_{\mathrm{irr}}-\frac{1-e^{-\lambda_{i, \mathrm{eff}} t_{\mathrm{irr}}}}{\lambda_{i, \mathrm{eff}}}\right),
$$

where $Y_{i}$ is the production yield for the radionuclide $i, \lambda_{i}$ its decay constant, $\lambda_{i, \text { eff }}$ its effective decay constant (corresponding to the sum of $\lambda_{i}$ and the air changes provided by the ventilation system per unit time, expressed in the same unit of $\left.\lambda_{i}\right), I$ the beam intensity, $Q$ the ventilation rate, $V$ the target area volume (about $1200 \mathrm{~m}^{3}$ ), and $t_{\text {irr }}$ the irradiation time (assumed to be 200 days per year). In case of operation with the new target, the total released activity is about $3.9 \mathrm{TBq}$ per year, which is about $20 \%$ lower than the one of
Target \#2 (i.e., $4.6 \mathrm{TBq}$ per year). In both cases, as shown in Table $\mathrm{V}$, the released activity is dominated by ${ }^{41} \mathrm{Ar}(45 \%$ for Target \#3 and $62 \%$ for Target \#2). For Target \#3, the production of air spallation products is about $20 \%$ higher; however, the ${ }^{41} \mathrm{Ar}$ production decreases by more than $70 \%$ because of a lower production of thermal neutrons.

In conclusion, the new target and its shielding reduce the radioactive emissions due to air activation from the $\mathrm{n}_{-} \mathrm{TOF}$ facility to the environment.

\section{Radioactive waste aspects}

In view of the final target disposal, the use of aluminum over steel for the target vessel would offer reduced activation and residual dose rate, but lead to additional constraints that would cancel these benefits. Chemical reactions may happen between aluminum and the concrete-based mortar used to prepare the waste, producing hydrogen gas that may damage the package in the long term $[46,47]$. For this reason, it was decided to limit the amount of aluminum in the new target and to build the new vessel in stainless steel. The main cause of the higher residual dose rate of stainless steel is its cobalt content, with the production of ${ }^{60} \mathrm{Co}$ from thermal neutron capture on ${ }^{59} \mathrm{Co}$. To reduce this contribution, the target vessel is built using stainless steel with cobalt content lower than $0.1 \%$. FLUKA simulations were performed to compare the residual dose rate after ten years of irradiation (target lifetime) at $2.5 \times 10^{19}$ protons on target per year and three years of cooldown time (time elapsed between the end of target operation and its shipping to the repository for long term storage). Figure 26 shows that the new target induces a higher maximum residual dose rate by a factor of 10 on the side of the proton beam window of the vessel. These results

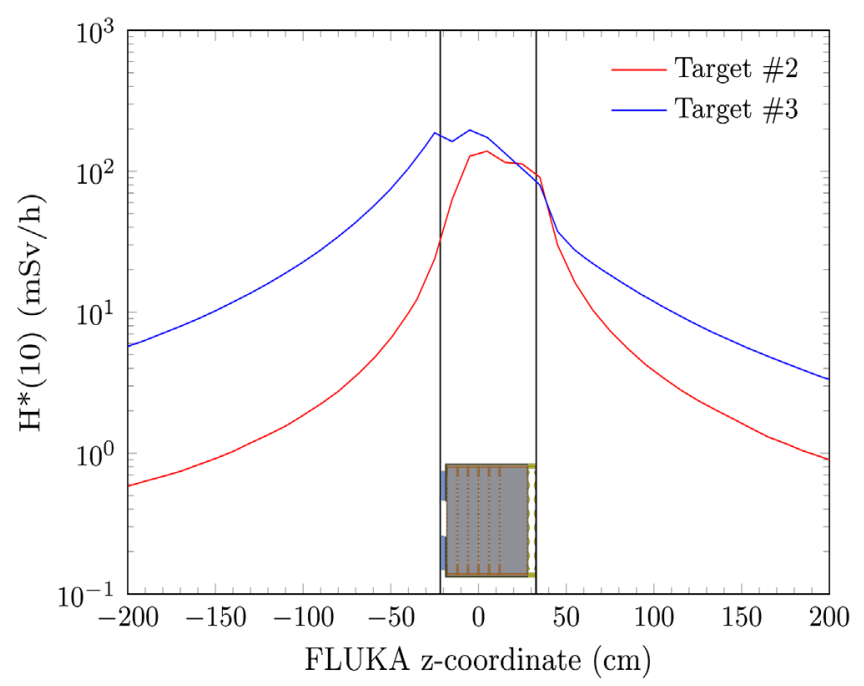

FIG. 26. Comparison of the residual dose rate after ten years of irradiation at $2.5 \times 10^{19}$ protons on target per year and three years of cooldown time for Target \#2 (red) and Target \#3 (blue). 
must be taken into account to plan and optimize the target final disposal.

\section{CONCLUSIONS}

An upgrade of the n_TOF facility took place during the CERN Long Shutdown 2 (2019-2021). A major part of the upgrade was the installation of the third-generation neutron spallation target, along with a new nitrogen cooling station and movable target shielding. The new target is based on pure lead cooled by nitrogen gas, a low-cobalt stainless steel vessel, and two water moderators for the two experimental areas of the facility. The nitrogen cooling system replaced the water cooling system of the previous targets, which was the cause of water corrosion and contamination with lead spallation products. This paper presented an overview of the studies leading to the final target design, with details on the physics performance, the mechanical design, the thermomechanical aspects, the cooling station, and the radiation protection aspects.

\section{ACKNOWLEDGMENTS}

The authors would like to acknowledge the support and inspiration of the n_TOF collaboration in order to reach the current design of this third-generation neutron spallation target. The project warmly recognizes the financial support provided by the CERN Accelerators Consolidation Project and specifically by M. Benedikt, R. Trant and M. Lamont. R. Logé wishes to thank PX Group for the generous support to the PX Group Chair. M. Calviani acknowledges the support and suggestions from the review panel members that helped the project advance and deliver the final product.

[1] D. Filges and F. Goldenbaum, Handbook of Spallation Research: Theory, Experiments and Applications (WileyVCH, Berlin, 2009), 10.1002/9783527628865.ch1.

[2] C. Rubbia et al., A high resolution spallation driven facility at the CERN-PS to measure neutron cross sections in the interval from $1 \mathrm{eV}$ to $250 \mathrm{MeV}$, Report No. CERN-LHC-98002-EET, CERN, 1998, https://cds.cern.ch/record/357112.

[3] M. Mosconi et al. (n_TOF Collaboration), Neutron physics of the Re/Os clock. I. Measurement of the $(n, \gamma)$ cross sections of ${ }^{186,187,188}$ Os at the CERN n_TOF facility, Phys. Rev. C 82, 015802 (2010).

[4] N. Colonna, F. Gunsing, and E. Chiaveri, The second beam line and experimental area at n_TOF: A new opportunity for challenging neutron measurements at CERN, Nucl. Phys. News 25, 19 (2015).

[5] L. Damone et al. (n_TOF Collaboration), ${ }^{7} \mathrm{Be}(n, p){ }^{7} \mathrm{Li}$ Reaction and the Cosmological Lithium problem: Measurement of the Cross Section in a Wide Energy Range at n_TOF at CERN, Phys. Rev. Lett. 121, 042701 (2018).

[6] C. Guerrero et al. (n_TOF Collaboration), Neutron Capture on the $s$-Process Branching Point ${ }^{171} \mathrm{Tm}$ via Time of Flight and Activation, Phys. Rev. Lett. 125, 142701 (2020).
[7] C. Borcea et al., Results from the commissioning of the n_TOF spallation neutron source at CERN, Nucl. Instrum. Methods Phys. Res., Sect. A 513, 524 (2003).

[8] R. Esposito and M. Calviani, Design of the thirdgeneration neutron spallation target for the CERN's n_TOF facility, J. Neutron Res. 22, 221 (2020).

[9] M. Barbagallo et al., High-accuracy determination of the neutron flux at n_TOF, Eur. Phys. J. A 49, 156 (2013).

[10] R. Catherall, Isolde and n_TOF consolidation, in Proceedings of the Chamonix 2014 Workshop on LHC Performance (CERN, Geneva, 2015), http://cds.cern.ch/record/ 2031218.

[11] N. Colonna, F. Gunsing, and F. Käppeler, Neutron physics with accelerators, Prog. Part. Nucl. Phys. 101, 177 (2018).

[12] J. M. Salome and R. Cools, Neutron producing targets at GELINA, Nucl. Instrum. Methods 179, 13 (1981).

[13] M. Febvre, Manufacturing and supply of a mercury cooled rotary uranium target for the GELINA accelerator facility of IRMM, in the 2009 1st International Conference on Advancements in Nuclear Instrumentation, Measurement Methods and their Applications (IEEE, Piscataway, New Jersey, 2009), 10.1109/ ANIMMA.2009.5503818.

[14] Y. Danon, R. Block, and R. Slovacek, Design and construction of a thermal neutron target for the RPI linac, Nucl. Instrum. Methods Phys. Res., Sect. A 352, 596 (1995).

[15] M. E. Overberg, B. E. Moretti, R. E. Slovacek, and R. C. Block, Photoneutron target development for the RPI linear accelerator, Nucl. Instrum. Methods Phys. Res., Sect. A 438, 253 (1999).

[16] S. F. Nowicki, S. A. Wender, and M. Mocko, The Los Alamos Neutron Science Center spallation neutron sources, Phys. Procedia 90, 374 (2017).

[17] G. S. Bauer, Overview on spallation target design concepts and related materials issues, J. Nucl. Mater. 398, 19 (2010).

[18] R. Beyer et al., Characterization of the neutron beam at nELBE, Nucl. Instrum. Methods Phys. Res., Sect. A 723, 151 (2013).

[19] K. Thomsen, M. Butzek, F. Gallmeier, and J. Wolters, A case for a SINQ-type cannelloni target at the ESS power level, Nucl. Instrum. Methods Phys. Res., Sect. A 625, 5 (2011).

[20] D. Kiselev, P. Baumann, B. Blau, K. Geissmann, D. Laube, T. Reiss, R. Sobbia, A. Strinning, V. Talanov, and M. Wohlmuther, The meson target stations and the high power spallation neutron source SINQ at PSI, J. Radioanal. Nucl. Chem. 305, 769 (2015).

[21] M. Wohlmuter, S. Dementjevs, P. Vontobel, J. Hovind, P. Trtik, and E. H. Lehmann, Investigation of SINQ (lead/ Zircaloy) spallation target structures by means of neutron imaging techniques, Mater. Res. Soc. Symp. Proc. 15, 287 (2020).

[22] D. Rochman, R. C. Haight, J. M. O' Donnell, A. Michaudon, S. A. Wender, D. J. Vieira, E. M. Bond, T. A. Bredeweg, A. Kronenberg, J. B. Wilhelmy, T. Ethvignot, T. Granier, M. Petit, and Y. Danon, Characteristics of a lead slowing-down spectrometer coupled to the LANSCE accelerator, Nucl. Instrum. Methods Phys. Res., Sect. A 550, 397 (2005). 
[23] F. Gunsing et al. (n_TOF Collaboration), Nuclear data activities at the n_TOF facility at CERN, Eur. Phys. J. Plus 131, 371 (2016).

[24] M. Sabaté-Gilarte et al., High-accuracy determination of the neutron flux in the new experimental area n_TOFEAR2 at CERN, Eur. Phys. J. A 53, 210 (2017).

[25] A. Ferrari, P. R. Sala, A. Fassò, and J. Ranft, FLUKA: A Multiparticle Transport Code (Program Version 2005) (CERN, Geneva, 2005), http://cds.cern.ch/record/898301.

[26] T. T. Böhlen, F. Cerutti, M. P. W. Chin, A. Fassò, A. Ferrari, P. G. Ortega, A. Mairani, P. R. Sala, G. Smirnov, and V. Vlachoudis, The FLUKA code: Developments and challenges for high energy and medical applications, Nucl. Data Sheets 120, 211 (2014).

[27] C. Guerrero, A. Tsinganis, E. Berthoumieux, M. Barbagallo, F. Belloni, F. Gunsing, C. Weiß, E. Chiaveri, M. Calviani, and V. Vlachoudis et al., Performance of the neutron time-of-flight facility n_TOF at CERN, Eur. Phys. J. A 49, 27 (2013).

[28] Ansys, Inc., https://www.ansys.com.

[29] F. R. Menter, Zonal two equation k- $\omega$ turbulence models for aerodynamic flows, in the 23rd Fluid Dynamics, Plasmadynamics, and Lasers Conference (American Institute of Aeronautics and Astronautics (AIAA), Orlando, 2012), 10.2514/6.1993-2906.

[30] V. Gnielinski, Heat Exchanger Design Handbook (Begell House Inc., New York, 2014), Chap. 1, 10.1615/ hedhme.a.000168.

[31] W. M. Rohsenow, J. P. Hartnett, and Y. I. Cho, Handbook of Heat Transfer, 3rd ed. (McGraw-Hill Education, New York, 1998), https://www.accessengineeringlibrary .com/content/book/9780070535558.

[32] I. E. Idelchik, Handbook of Hydraulic resistance (2nd revised and enlarged edition) (Hemisphere Publishing Corp., Washington, 1986).

[33] ASHRAE Duct Fitting Database (American Society of Heating, Refrigerating and Air-Conditioning Engineers, Inc., Atlanta, Georgia, 2009).

[34] Recommended Practice for Design and Installation of Offshore Production Platform Piping Systems, 5th ed., API RP 14E (American Petroleum Institute, Dallas, Texas, 2013).

[35] R. Feder and A.S. Nowick, Use of thermal expansion measurements to detect lattice vacancies near the melting point of pure lead and aluminum, Phys. Rev. 109, 1959 (1958).

[36] C. Y. Ho, R. W. Powell, and P. E. Liley, Thermal conductivity of the elements, J. Phys. Chem. Ref. Data 1, 279 (1972).
[37] B. J. McBride, S. Gordon, and M. A. Reno, Coefficients for calculating thermodynamic and transport properties of individual species, NASA Lewis Research Center Technical Report No. NASA-TM-4513, Cleveland, OH, 1993, https://ntrs.nasa.gov/citations/19940013151.

[38] W. Hofmann and G. Vibrans, Lead and Lead Alloys: Properties and Technology (Springer-Verlag, Berlin, 1970), https:// www.springer.com/la/book/9783662270301.

[39] H. J. Rack and G. A. Knorovsky, Assessment of stressstrain data suitable for finite-element elastic-plastic analysis of shipping containers, Sandia Laboratory Technical Report No. SAND-77-1872, Albuquerque, NM, 1978, https://www.osti.gov/biblio/6513543.

[40] H. J. Frost and M. F. Ashby, Deformation-Mechanism Maps: The Plasticity and Creep of Metals and Ceramics (Pergamon Press, Oxford, UK, 1982), https://engineering .dartmouth.edu/defmech/.

[41] J. Lemaitre and J.-L. Chaboche, Mechanics of Solid Materials (Cambridge University Press, Cambridge, England, 1990), 10.1017/CBO9781139167970.

[42] I. Efthymiopoulos, C. Hessler, H. Gaillard, D. Grenier, M. Meddahi, P. Trilhe, A. Pardons, C. Theis, N. Charitonidis, S. Evrard, H. Vincke, and M. Lazzaroni, HiRadMat: A new irradiation facility for material testing at CERN, in Proceedings of the 2nd International Particle Accelerator Conference, San Sebastián, Spain (EPS-AG, Spain, 2011), https://accelconf.web.cern.ch/IPAC2011/papers/TUPS058 .pdf.

[43] n_TOF Collaboration, The new n_TOF NEAR station, Reports No. CERN-INTC-2020-073 and No. INTC-I-222, CERN, Geneva, 2020, https://cds.cern.ch/record/2737308.

[44] H. Vincke and C. Theis, Actiwiz-Optimizing your nuclide inventory at proton accelerators with a computer code, Prog. Nucl. Sci. Tech. 4, 228 (2014).

[45] S. Agosteo, Radiation protection constraints for use of proton and ion accelerators in medicine, Radiation Protection Dosimetry 137, 167 (2009).

[46] S.-I. Pyun and S.-M. Moon, Corrosion mechanism of pure aluminum in aqueous alkaline solution, J. Solid State Electrochem. 4, 267 (2000).

[47] C. Mendibide, V. Dusquesnes, V. Deydier, X. Bourbon, and D. Crusset, Corrosion behavior of aluminum alloy 5754 in cement-based matrix-simulating nuclear waste disposal conditions, Mater. Corros. 72, 383 (2021).

Correction: The previously published Fig. 8 contained an error in the abscissa units and has been replaced. 